\title{
A Critical Role for the GluAI Accessory Protein, SAP97, in Cocaine Seeking
}

\author{
Samantha L White', Pavel I Ortinski', Shayna H Friedman', Lei Zhang ${ }^{3}$, Rachael L Neve ${ }^{4}$, Robert G Kalb ${ }^{3}$, \\ Heath D Schmidt' and R Christopher Pierce*,I \\ 'Department of Psychiatry, Center for Neurobiology and Behavior, Perelman School of Medicine at the University of Pennsylvania, Philadelphia, \\ PA, USA; 'Department of Pharmacology, Physiology and Neuroscience, University of South Carolina School of Medicine, Columbia, SC, USA; \\ ${ }^{3}$ Department of Neurology, Perelman School of Medicine at the University of Pennsylvania, Abramson Research Center 814, Philadelphia, PA, USA; \\ ${ }^{4}$ Department of Brain and Cognitive Sciences, McGovern Institute for Brain Research at the Massachusetts Institute of Technology, Cambridge, \\ MA, USA
}

\begin{abstract}
A growing body of evidence indicates that the transport of GluAI subunit-containing calcium-permeable AMPA receptors (CP-AMPARs) to synapses in subregions of the nucleus accumbens promotes cocaine seeking. Consistent with these findings, the present results show that administration of the CP-AMPAR antagonist, Naspm, into the caudal lateral core or caudal medial shell of the nucleus accumbens attenuated cocaine priming-induced reinstatement of drug seeking. Moreover, viral-mediated overexpression of 'pore dead' GluAl subunits (via herpes simplex virus (HSV) GluA I-Q582E) in the lateral core or medial shell attenuated the reinstatement of cocaine seeking. The overexpression of wild-type GluAI subunits (via HSV GluAI-WT) in the medial shell, but not the lateral core, enhanced the reinstatement of cocaine seeking. These results indicate that activation of GluAI-containing AMPARs in subregions of the nucleus accumbens reinstates cocaine seeking. SAP97 and 4.I N are proteins involved in GluA I trafficking to and stabilization in synapses; SAP97GluAI interactions also influence dendritic growth. We next examined potential roles of SAP97 and 4.IN in cocaine seeking. Viralmediated expression of a microRNA that reduces SAP97 protein expression (HSV miSAP97) in the medial accumbens shell attenuated cocaine seeking. In contrast, a virus that overexpressed a dominant-negative form of a 4.I N C-terminal domain (HSV 4.IN-CTD), which prevents endogenous 4.IN binding to GluAI subunits, had no effect on cocaine seeking. These results indicate that the GluAI subunit accessory protein SAP97 may represent a novel target for pharmacotherapeutic intervention in the treatment of cocaine craving. Neuropsychopharmacology (2016) 4I, 736-750; doi:I 0.1 038/npp.20I5.199; published online 29 July 2015
\end{abstract}

\section{INTRODUCTION}

Nucleus accumbens AMPA receptors (AMPARs) play a critical role in the reinstatement of cocaine seeking, an animal model of relapse. The nucleus accumbens is divided into two major subregions, the core and shell. Increased AMPA receptor transmission in both accumbens subregions contributes to cocaine reinstatement (Schmidt and Pierce, 2010). Thus, microinjection of the AMPA receptor antagonist, CNQX, into either the core or shell attenuated cocaine priming-induced reinstatement (Famous et al, 2008). Consistent with these findings, administration of AMPA itself into either accumbens subregion elicited cocaine seeking (Ping et al, 2008).

* Correspondence: Dr RC Pierce, Department of Psychiatry, Center for Neurobiology and Behavior, Perelman School of Medicine at the University of Pennsylvania, 125 South 31 st Street, Philadelphia, PA 19104, USA, Tel: +2I5 746 89I5, Fax: +2I5 573 7605,

E-mail: rcpierce@mail.med.upenn.edu

Received 26 December 2014; revised 5 June 2015; accepted 6 June 2015; accepted article preview online 7 July 2015
There are four AMPA receptor subunits, GluA1-4. All AMPARs become permeable to sodium and potassium on activation. However, the absence of GluA2 subunits from the AMPAR tetramer results in calcium permeability. GluA2lacking calcium-permeable AMPARs (CP-AMPARs) have larger single channel conductance and faster kinetics relative to calcium-impermeable (CI) AMPARs that include GluA2 subunits (Cull-Candy et al, 2006; Lee, 2012; Tanaka et al, 2000). The balance of AMPARs in the nucleus accumbens is shifted to CP-AMPARs following extended-access cocaine self-administration followed by a prolonged period of forced cocaine abstinence. Thus, increased cell surface GluA1, but not GluA2, expression was observed in the nucleus accumbens (Conrad et al, 2008) and electrophysiological studies demonstrated inward rectification of evoked AMPA receptor EPSCs, a hallmark of CP-AMPARs, in the accumbens of cocaine-experienced rats (Conrad et al, 2008; McCutcheon et al, 2011c). These increases in accumbens CP-AMPAR expression and function were behaviorally relevant in that microinjection of the CP-AMPAR antagonist Naspm into the accumbens core blocked incubated cueinduced cocaine seeking (Conrad et al, 2008). Interestingly, 
short-access ( $2 \mathrm{~h} /$ day) cocaine self-administration had no influence on CP-AMPAR-mediated transmission in the nucleus accumbens (Purgianto et al, 2013), which indicates that extended-access ( $6 \mathrm{~h} /$ day) cocaine self-administration in adult rats is required to produce prolonged increases in CPAMPAR function in the absence of extinction (Wolf and Tseng, 2012).

A separate line of investigation revealed that dynamic changes in accumbens AMPAR transmission contribute to the reinstatement of cocaine seeking following extinction of short-access cocaine self-administration. Under extinction conditions, drug seeking promoted by non-contingent cocaine administration was associated with increased surface expression of GluA1 subunits in the accumbens shell (Anderson et al, 2008). Moreover, suppression of accumbens GluA1 transcription (Ping et al, 2008) or impairment of the transport of GluA1-containing AMPA receptors to synapses in the accumbens shell during extinction (Anderson et al, 2008) attenuated the reinstatement of drug seeking induced by a cocaine-priming injection. To expand on these findings, the current experiments used pharmacological and viral vector approaches to assess the role of GluA1-mediated transmission in accumbens subregions in cocaine seeking using a short-access self-administration/extinction/reinstatement paradigm.

The mechanisms underlying the enhanced role of accumbens GluA1-containing AMPARs during cocaine priming-induced reinstatement of drug seeking remain unclear. SAP97 is a membrane-associated guanylyl kinase (MAGUK) protein that is sufficient (Cai et al, 2002; Howard et al, 2010), if not always necessary (Kim et al, 2005), for trafficking of GluA1-containing AMPARs to synapses. Similarly, $4.1 \mathrm{~N}$ is an actin-binding protein that also contributes to the trafficking and stabilization of GluA1containing AMPARs at the cell surface (Lin et al, 2009; Shen et al, 2000). Both SAP97-GluA1 and 4.1N-GluA1 interactions contribute to various forms of neuronal plasticity (Lin et al, 2009; Zheng et al, 2011; Zheng and Keifer, 2014). Here, viral vectors were used to reduce SAP97 expression or impair the interaction between $4.1 \mathrm{~N}$ and GluA1 subunits prior to reinstatement test sessions to determine the functional significance of these accessory proteins in cocaine seeking.

\section{MATERIALS AND METHODS}

\section{Animals and Housing}

Male Sprague-Dawley rats (Rattus novergicus) weighing 225$250 \mathrm{~g}$ were obtained from Taconic Laboratories (Germantown, NY). Animals were individually housed with food and water available ad libitum. A $12 \mathrm{~h}$ light/dark cycle was used and all experiments were performed during the light cycle. All experiments used Med-Associates (East Fairfield, VT) operant chambers equipped with response levers, a house light and a pump for injecting drugs intravenously. Operant chambers were enclosed within ventilated, sound-attenuating chambers. All experimental procedures were consistent with the ethical guidelines of the US National Institutes of Health and were approved by the Perelman School of Medicine Institutional Animal Care and Use Committee at the University of Pennsylvania.

\section{Drugs and Viruses}

Cocaine hydrochloride was obtained from the National Institute on Drug Abuse (Rockville, MD) and dissolved in bacteriostatic $0.9 \%$ saline. The first experiments examined the role of accumbens CP-AMPARs in cocaine reinstatement. 1-Naphthyl acetyl spermine trihydrochloride (Naspm) is a synthetic analog of Joro spider toxin that acts as a CPAMPAR antagonist (Tsubokawa et al, 1995). Naspm was obtained from Sigma-Aldrich (St Louis, MO) and was dissolved in phosphate-buffered saline (PBS). In the nucleus accumbens, CP-AMPARs are either GluA1 homomers or GluA1/A3 heteromers (Boudreau et al, 2007). Therefore, we next manipulated GluA1 expression in the accumbens prior to cocaine reinstatement using viral vectors. All constructs were packaged into a herpes simplex virus (HSV) p1005 plasmid, driven by an IE $4 / 5$ promoter. The first virus produces 'pore dead' GluA1 subunits (Bachtell et al, 2008). These pore dead GluA1 subunits have a mutation of the glutamine (Q) at site 582 to a glutamic acid (E) (ie, GluA1Q582E). This amino-acid residue is part of the pore-forming region. As glutamine is a polar, uncharged amino acid, whereas glutamic acid is negatively charged, this mutation results in GluA1-Q582E-containing AMPA receptors that cannot pass ions (Dingledine et al, 1999). An HSV that overexpresses wild-type GluA1 (GluA1-WT) was generated for the next experiment (Carlezon et al, 1997). The final two experiments used viral vectors to manipulate the GluA1 accessory proteins $4.1 \mathrm{~N}$ or SAP97. The $4.1 \mathrm{~N}$ virus $(4.1 \mathrm{~N}-$ CTD) overexpresses a dominant-negative form of the $4.1 \mathrm{~N}$ C-terminal domain (residues 744-879), which binds GluA1 subunits and prevents interaction with endogenous 4.1N (Fukatsu et al, 2004; Shen et al, 2000). For SAP97, the HSV virus expresses a miRNA (5'-CAGTGACTGCCTTA AAGAATA-3') against SAP97, which suppresses translation of the SAP97 protein (both isoforms) (Zhang et al, 2015). All viruses were designed to co-express enhanced green fluorescent protein (eGFP) driven by a separate CMV promoter. Control viruses express a scrambled sequence plus eGFP.

\section{Surgery}

Rats were handled daily and allowed 1 week to acclimate to their home cages on arrival. Prior to all surgeries, rats were anesthetized with $80 \mathrm{mg} / \mathrm{kg}$ ketamine (i.p.; Sigma-Aldrich) and $12 \mathrm{mg} / \mathrm{kg}$ xylazine (i.p.; Sigma-Aldrich). An indwelling silastic catheter (CamCaths, UK) was inserted into the right jugular vein and sutured in place. The catheter was routed to a mesh backmount platform that was implanted subcutaneously dorsal to the shoulder blades. Catheters were flushed daily with $0.3 \mathrm{ml}$ of an antibiotic (Timentin, $0.93 \mathrm{mg} / \mathrm{ml}$, Henry Schein, Melville, NY) dissolved in heparinized saline. The catheters were sealed with plastic obturators when not in use.

For animals destined for the Naspm experiments, immediately following catheter insertion the rats were mounted in a stereotaxic apparatus and two stainless-steel guide cannulae (24 gauge) were implanted bilaterally $2 \mathrm{~mm}$ dorsal to the medial nucleus accumbens shell, accumbens core or dorsal striatum. Guide cannulae were cemented in place by affixing dental acrylic to stainless-steel screws 
secured in the skull. The coordinates for the ventral ends of the guide cannulae, relative to bregma (Paxinos and Watson, 1997), were as follows: accumbens shell $=+1.0 \mathrm{~mm} \mathrm{~A} / \mathrm{P}$, $\pm 1.0 \mathrm{~mm} \mathrm{M} / \mathrm{L},-5.0 \mathrm{~mm} \mathrm{D} / \mathrm{V}$; accumbens core $=+1.0 \mathrm{~mm}$ $\mathrm{A} / \mathrm{P}, \pm 2.5 \mathrm{~mm} \mathrm{M} / \mathrm{L},-5.0 \mathrm{~mm} \mathrm{D} / \mathrm{V}$; dorsal striatum $=+1.0$ $\mathrm{mm} \mathrm{A} / \mathrm{P}, \pm 3.0 \mathrm{~mm} \mathrm{M} / \mathrm{L},-2.0 \mathrm{~mm} \mathrm{D} / \mathrm{V}$. An obturator (33-gauge wire) was inserted into each guide cannula to prevent occlusion.

\section{Cocaine Self-Administration and Extinction}

Following a 7-day recovery period from surgery, rats were placed in operant chambers and allowed to lever press for intravenous cocaine infusions $(0.25 \mathrm{mg} / 59 \mu \mathrm{l}$ saline over $5 \mathrm{~s})$ over a 2-h time period daily for 21 days. Each selfadministration session began with the i.v. administration of $59 \mu \mathrm{l}$ cocaine $(0.25 \mathrm{mg})$ to fill the catheter. Rats initially selfadministered cocaine under a fixed ratio (FR) 1 schedule of reinforcement (limited to 30 injections per $120 \mathrm{~min}$ ). Once animals achieved stable responding, as defined by at least 20 infusions over the $2 \mathrm{~h}$ session for 2 consecutive days, they were transitioned to a FR5 schedule of reinforcement (and again limited to 30 injections per $120 \mathrm{~min}$ ). In our experience, use of an FR5 self-administration schedule results in more robust reinstatement responses subsequently. For both schedules of reinforcement, a $20 \mathrm{~s}$ time-out period followed each cocaine infusion, during which time active, drug-paired lever responses were tabulated but had no scheduled consequence. Each operant chamber was also equipped with an inactive lever. Responses made on the inactive lever, which had no scheduled consequence, were also recorded during all self-administration sessions. Following 21 days of cocaine self-administration, drug-taking behavior was extinguished by replacing cocaine with $0.9 \%$ bacteriostatic saline. Extinction continued until responding on the active lever was $<15 \%$ of the responses on the last day of cocaine self-administration.

\section{Sucrose Self-Administration and Extinction}

After a 7-day post-surgery recovery period, rats were food deprived $(15-20 \mathrm{~g}$ of lab chow daily, Harlan Teklad, Wilmington, DE) and allowed to administer sucrose pellets on an FR1 schedule, where they received one 45-mg sucrose pellet (Research Diets, New Brunswick, NJ) each time they pressed the active lever. After receiving over 20 pellets per session over two consecutive self-administration sessions, the rats then advanced to an FR5 schedule. Rats selfadministered sucrose pellets for a total of 14 days with a maximum of 30 pellets per session. Following 14 days of sucrose self-administration, the subjects were shifted into extinction where active lever pressing no longer resulted in sucrose pellet administration. Extinction of sucrose-taking behavior continued until responding on the active lever was $15 \%$ or less of that on the last self-administration day.

\section{Cocaine and Sucrose Reinstatement-Naspm Microinjections}

During the reinstatement phase, the obturators were removed from the guide cannulae and 33-gauge stainlesssteel microinjectors (Small Parts, Logansport, IN) were inserted into the guide cannula. The microinjectors extended $2 \mathrm{~mm}$ below the ventral end of the guide cannulae into the caudal medial nucleus accumbens shell, caudal lateral accumbens core, or dorsal striatum. Bilateral infusions of $0.5 \mu \mathrm{l}$ of Naspm $(40 \mu \mathrm{g})$ or PBS occurred over a 120-s time period. This dose of Naspm was previously shown to modulate cocaine-mediated behavior (Conrad et al, 2008). Following microinfusion of either Naspm or PBS, the microinjectors remained in place for $60 \mathrm{~s}$ to allow the solution to diffuse away from the tips of the microinjectors before removal. For cocaine reinstatement, $10 \mathrm{~min}$ following microinjection a systemic priming injection of cocaine $(10 \mathrm{mg} / \mathrm{kg}$, i.p.) was administered immediately prior to a reinstatement test session. For sucrose reinstatement, the experimenter remotely administered one sucrose pellet every $2 \mathrm{~min}$ for the first $10 \mathrm{~min}$ of the reinstatement test session.

During the cocaine reinstatement test sessions, satisfaction of the response requirement (ie, five presses on the active lever) resulted in saline rather than cocaine infusion. During sucrose reinstatement active lever responses had no scheduled consequences. For both cocaine and sucrose reinstatement, each reinstatement test session was followed by extinction sessions until responding was again $<15 \%$ of the response rate maintained by cocaine or sucrose selfadministration. Generally, 1-2 days of extinction were necessary to reach extinction criterion between reinstatement test sessions. The FR5 schedule was used throughout the extinction and reinstatement phases of these experiments. Naspm or PBS were administered during the reinstatement phase in a counterbalanced fashion.

\section{Cocaine and Sucrose Reinstatement-Viral Vectors}

Only one viral vector or its control was microinjected bilaterally per animal in a between-subjects design. Following recovery from surgery the obturators were removed from the guide cannulae and 33-gauge stainless-steel microinjectors were inserted into the caudal lateral nucleus accumbens core or caudal medial shell as described above. Bilateral infusions of HSV GluA1-Q582E, HSV GluA1-WT, HSV 4.1N-CTD, HSV eGFP, HSV miSAP97, or HSV scrambled miSAP97 occurred over a 10-min time period for a total volume of $2.0 \mu \mathrm{l}$ per side. Following the injections, microinjectors were left in place for $120 \mathrm{~s}$ to allow the solution to diffuse away from the tips of the cannula before they were removed. Animals underwent daily extinction sessions until reaching the first reinstatement test session 3 days (GluA1-Q582E, GluA1-WT, 4.1N-CTD) or 4 days (miSAP97, scramble) post infusion (see Results for additional details). Animals then underwent daily extinction sessions until the second reinstatement test 7 days post injection. Cocaine and sucrose reinstatement were precipitated as described above.

\section{Verification of Cannulae Placements}

After the completion of all behavioral experiments, the animals were given an overdose of pentobarbital $(100 \mathrm{mg} / \mathrm{kg}$, i.p.) and brains were removed and stored in formalin for at least 3 days. Subsequently, coronal sections $(100 \mu \mathrm{m})$ were taken at the level of the striatum with a Vibratome (Technical Products International; St Louis, MO). The sections were mounted on gelatin-coated slides. Cannula 
placements as well as potential drug- or cannula-induced neuronal damage were subsequently assessed. Cell death and associated gliosis also were determined. Animals with cannulae placements outside of the areas of interest, or with excessive mechanical damage/gliosis, were excluded from subsequent data analysis.

\section{Viral Expression}

To ascertain viral expression via green fluorescent protein, we injected $(2 \mu \mathrm{l} /$ side) HSV GluA1-Q582E, HSV GluA1-WT, HSV 4.1N-CTD, or HSV miSAP97 into the nucleus accumbens of separate, drug-naive rats. At 3 days (HSV GluA1-Q582E, HSV GluA1-WT, HSV 4.1N-CTD), 4 days (HSV miSAP97), or 7 days (all viruses) after injection, animals received $100 \mathrm{mg} / \mathrm{kg}$ pentobarbital (i.p.) before perfusion with $120 \mathrm{ml}$ ice-cold PBS followed by $60 \mathrm{ml} 4 \%$ PFA dissolved in ice-cold PBS. Brains were removed and placed in $4 \%$ PFA for $24 \mathrm{~h}$ before storage in 30\% sucrose dissolved in PBS with $1 \%$ sodium azide. Coronal sections $(10-30 \mu \mathrm{m})$ were taken using a cryostat (Cryotome FE, Thermo Fisher Scientific, Waltham, MA) and mounted directly onto polarized glass slides. Dry slides were washed in $1 \times$ PBS, and then blocked for $1 \mathrm{~h}$ in $0.1 \%$ triton and $3 \%$ normal donkey serum in $1 \times$ PBS. We then added primary antibody (Anti-GFP, Ms/Rb-Millipore, Billerica, MAdiluted $1: 1000$ in $0.1 \%$ triton $+3 \%$ donkey serum in PBS) to the slides and incubated overnight at $4{ }^{\circ} \mathrm{C}$. The next day, the slides were washed in $1 \times$ PBS before incubation in secondary fluorescent antibody at room temperature for $2 \mathrm{~h}$ (Alexa Fluor 488, 1:500, Jackson ImmunoResearch, West Grove, PA). After $2 \mathrm{~h}$, slides were washed in $1 \times$ PBS before being cover-slipped using Vectashield mounting medium (Vector Laboratories, Burlingame, CA) and imaged for GFP expression using fluorescent microscopy.

\section{Electrophysiology}

Separate, drug-naive rats received bilateral injections of HSV GluA1-Q582E or GluA1-WT $(2 \mu \mathrm{l})$ into the medial accumbens shell. After 3 days, animals were decapitated under isofluorane anesthesia and brain slices prepared as described previously (Ortinski et al, 2013). In brief, the brain was removed and coronal slices $(300 \mu \mathrm{m})$ containing the nucleus accumbens were cut with a Vibratome (VT1000S, Leica Microsystems) in ice-cold artificial cerebrospinal fluid solution (ACSF), in which $\mathrm{NaCl}$ was replaced by an equiosmolar concentration of sucrose. ACSF consisted of $130 \mathrm{mM} \mathrm{NaCl}, 3 \mathrm{mM} \mathrm{KCl}, 1.25 \mathrm{mM} \mathrm{NaH} 2 \mathrm{PO} 4,26 \mathrm{mM}$ $\mathrm{NaHCO}$, $10 \mathrm{mM}$ glucose, $1 \mathrm{mM} \mathrm{MgCl} 2$, and $2 \mathrm{mM} \mathrm{CaCl} 2$ ( $\mathrm{pH}$ 7.2-7.4 when saturated with $95 \% \mathrm{O} 2 / 5 \% \mathrm{CO} 2$ ). Wholecell recordings were obtained using borosilicate glass pipettes filled with intracellular solution containing: $100 \mathrm{mM}$ $\mathrm{CsCH}_{3} \mathrm{O}_{3} \mathrm{~S}, 50 \mathrm{mM} \mathrm{CsCl}, 3 \mathrm{mM} \mathrm{KCl}, 0.2 \mathrm{mM}$ BAPTA, $10 \mathrm{mM}$ HEPES, $1 \mathrm{mM} \mathrm{MgCl}_{2}, 2.5 \mathrm{mM}$ phosphocreatine2Na, $2 \mathrm{mM}$ Mg-ATP, $0.25 \mathrm{mM}$ GTP-Tris, $1 \mathrm{mM}$ QX-314, $0.1 \mathrm{mM}$ spermine, adjusted to $\mathrm{pH}$ 7.2-7.3 with $\mathrm{CsOH}$ (osmolarity 280-290 mOsm). Slices were viewed using infrared differential interference contrast optics under an upright microscope (Eclipse FN1, Nikon Instruments) with a $40 \times$ water immersion objective. To avoid recording from damaged cells, neurons within $50 \mu \mathrm{M}$ of the injection cannula track were excluded from the analysis. There were no differences on any of the measures between eGFPnegative cells in slices exposed to GluA1-Q582E and GluA1WT. Therefore, these cells were pooled for analysis.

For evoked EPSCs (eEPSCs), a minimal stimulation intensity required to evoke a consistent post-synaptic response was determined. Peak eEPSC amplitudes were then measured at double and triple the minimal stimulation intensity (at $0.05-0.1 \mathrm{~Hz}$ ) to construct the input/output curves. Average responses were then calculated based on 5-10 eEPSCs at each stimulation intensity. The rectification index of AMPA receptor-mediated eEPSCs was measured as the ratio of the peak current amplitude at $-70 \mathrm{mV}$ to the peak current amplitude at $+40 \mathrm{mV}$. For rectification index, the measurements were based on 5-10 eEPSCs evoked at $0.1 \mathrm{~Hz}$.

\section{Western Blot}

Protein expression in the nucleus accumbens was assessed following HSV 4.1N-CTD HSV eGFP administration. Drugnaive animals received unilateral $2 \mu \mathrm{l}$ injections of $\mathrm{HSV}$ $4.1 \mathrm{~N}-\mathrm{CTD}$ or HSV miSAP97 into the medial accumbens shell in one hemisphere and HSV GFP into the medial shell of the other hemisphere. Following virus administration, the subjects were returned to their home cages for 3 days (HSV $4.1 \mathrm{~N}-\mathrm{CTD}$ ) or 4 days (HSV miSAP97). At this point, the rats were killed via rapid, live decapitation; brains were immediately extracted and flash-frozen in isopentane. $300 \mu \mathrm{M}$ sections containing the nucleus accumbens were subsequently taken using a cryostat and the medial accumbens shell was dissected before processing whole-cell tissue for western blot as described previously (Anderson et al, 2008).

For all samples, protein concentration was quantified using a Pierce BCA Protein Assay Kit (Thermo Fisher Scientific). Equal amounts of protein $(10-20 \mu \mathrm{g})$ were loaded and separated in 10\% Tris-Glycine gels (Life Technologies, Grand Island, NY) under reducing conditions, then transferred to nitrocellulose membranes using the i-Blot dry transfer system (Life Technologies). Membranes were blocked with Odyssey Blocking Buffer (Life Technologies), according to manufacturer instructions. Membranes were incubated overnight at $4{ }^{\circ} \mathrm{C}$ with selective antibodies to $4.1 \mathrm{~N}$ (Rb 1:1000, Millipore) or SAP97 (Rb 1:1000, Abcam, Cambridge, England) as well as GAPDH (1:2000, Cell Signaling, Danvers, MA) diluted in Odyssey Blocking Buffer. After washing with TBST, membranes were then incubated with infrared secondary antibodies at room temperature for $1 \mathrm{~h}$ (1:5000, IR-dye 680 or IR-dye 800) before being imaged on an Odyssey fluorescent scanner (Li-Cor Biotechnology, Lincoln, NE). GAPDH expression was used as a loading control; proteins were normalized to GAPDH-integrated intensity values.

We used hippocampal cultures to test the efficacy of the HSV miRNA toSAP97. Pure hippocampal cultures were obtained from the University of Pennsylvania Neuron Culture Core facility (http://www.med.upenn.edu/neurons rus/) and maintained in vitro for 14 days in Neurobasal media+B27 supplement. Cultures were infected with recombinant $\mathrm{HSV}$ at $1.5 \mu \mathrm{l}$ of virus $/ \mathrm{ml}$ of culture medium. Lysates were prepared 2 days later and subjected to western blot for SAP97 or actin. Each experiment was performed on four 
separate dishes of hippocampal neurons infected with either HSV-miRNA to SAP97 or HSV-miRNA scrambled and no fewer than three separate experimental determinations of miRNA efficacy were performed.

\section{RESULTS}

Blocking CP-AMPARs in the Accumbens Core or Shell, but not Dorsolateral Striatum, Attenuated Cocaine Priming-Induced Reinstatement of Drug Seeking

To assess the role of CP-AMPARs in the reinstatement of cocaine seeking, a CP-AMPAR antagonist (Naspm) was microinjected into regions of the striatal complex that contribute to various aspects of cocaine-seeking behavior. Total active and inactive lever responding (mean \pm SEM) during the reinstatement of cocaine seeking following microinjection of saline or $40 \mu \mathrm{g} \mathrm{Naspm}$ into the caudal lateral accumbens core, caudal medial accumbens shell, or DL striatum are shown Figure 1a-c, respectively. Reinstatement data were analyzed with three separate mixed factors analyses of variance (ANOVAs) with drug treatment as the between-subjects factor and lever as the within subjects factor. Analysis of the core data $(n=12)$ revealed significant main effects of treatment $\left(F_{1,22}=5.544, p<0.0279\right)$ and lever $\left(F_{1,22}=71.95, p<0.0001\right)$ as well as a significant treatment $\times$ lever interaction $\left(F_{1,22}=8.653, p<0.0075\right)$. Post hoc tests showed a significant difference in active lever responding between treatments (Bonferroni, $p<0.05$, Figure 1a). Analysis of the shell data $(n=8)$ showed significant main effects of treatment $\left(F_{1,14}=16.51, p<0.0012\right)$ and lever $\left(F_{1,14}=53.72, p<0.0001\right)$ as well as a significant treatment $\times$ lever interaction $\left(F_{1,14}=19.58, p<0.0006\right)$. Pairwise comparisons demonstrated a significant difference in active lever responding between treatments (Bonferroni, $p<0.05$, Figure $1 \mathrm{~b})$. Analysis of the DL striatum data $(n=4)$, which is shown in Figure 1c, revealed a significant main effect of lever $\left(F_{1,6}=41.0, p<0.0007\right)$ but no significant main effect of treatment and no significant treatment $\times$ lever interaction. The microinjection placements for the core, shell, and DL striatum are shown in Figure $1 \mathrm{~d}-\mathrm{f}$, respectively. Collectively, these data indicate that antagonism of CP-AMPARs in the caudal lateral accumbens core or caudal medial shell, but not the DL striatum, attenuates the reinstatement of cocaine seeking.

Decreases in responding, such as following intra-core or shell Naspm, could be due to generalized behavioral disruption. Although Naspm produced no effect on inactive lever responding, the low average number of inactive responses per session decreases the utility of this measure as a means to judge drug-induced behavioral suppression. Therefore, we also assessed the reinstatement of sucrose seeking. Total responses on the active lever (mean \pm SEM) during the sucrose reinstatement sessions are summarized in Table 1. Microinjection of Naspm into the medial shell had no influence on the reinstatement of sucrose seeking. However, intra-core Naspm significantly attenuated sucrose seeking, which indicates that CP-AMPARs in the lateral core may have a more generalized influence on motivated behaviors. These data were analyzed with separate unpaired $t$-tests, the results of which are included in Table 1.
Extinction of Cocaine Self-Administration had no Effect on CP-AMPAR Function in the Medial Accumbens Shell

In drug-naïve rats, CP-AMPARs in the nucleus accumbens account for $<10 \%$ of eEPSC amplitude (Conrad et al, 2008) and Naspm has a limited effect on eEPSCs in the caudal lateral accumbens core following short-access cocaine selfadministration in the absence of extinction (Purgianto et al, 2013). Therefore, it seems unlikely that the influence of Naspm on the cocaine reinstatement as shown in Figure 1 is due to blocking CP-AMPARs present in the nucleus accumbens prior to the reinstatement session. However, it is possible that the extinction of cocaine seeking behavior may increase CP-AMPARs in the nucleus accumbens. To investigate this possibility, we recorded from medial accumbens shell neurons in slices obtained from rats whose cocaine self-administration behavior was extinguished or control rats that received passive yoked saline infusions. We found no differences in rectification of AMPAR eEPSCs between these two groups. The rectification index $(-70 \mathrm{mV} /$ $+40 \mathrm{mV}$ ) data were as follows (mean \pm SEM): yoked saline, $2.366 \pm 0.189$ (12 cells from three animals); cocaine+extinction, $2.508 \pm 0.155$ (13 cells from three animals). An unpaired $t$-test showed no difference between these treatments. These data suggest that extinction of cocaine seeking does not affect the relative abundance of CP-AMPARs at excitatory synapses in the medial accumbens shell. As reviewed in more detail in the discussion section, it seems likely that Naspm is influencing accumbens CP-AMPARs that are transported transiently to the cell surface during the reinstatement of cocaine seeking.

\section{Over-Expression of 'Pore Dead' GluA1-Q582E Subunits in the Core or Shell Reversibly Attenuated Cocaine Seeking}

We initially characterized HSV GluA1-Q582E electrophysiologically in naive rats (ie, not exposed to cocaine) 3 days after microinjection of the virus into the nucleus accumbens. Representative examples of eEPSCs are shown in Figure 2. Quantification of this experiment is depicted in Figure $2 b$. These data were analyzed with a two-way ANOVA, which revealed significant main effects of treatment $\left(F_{1,16}=11.51\right.$, $p<0.0037)$ and stimulation intensity $\left(F_{2,32}=15.45\right.$, $p<0.0001)$ as well as a significant interaction between these factors $\left(F_{2,32}=7.63, p<0.0019\right)$. Subsequent pairwise tests showed a significant difference between amplitudes measured from eGFP-negative and eGFP-positive cells at the strongest stimulation intensity (Bonferroni, $p<0.0001$, Figure $2 b$ ). The magnitude of the decrease in eEPSC amplitude in eGFP-positive cells was somewhat surprising as HSV GluA1-Q582E shouldn't influence GluA2A3 expression. The rectification index also was measured in accumbens eGFP-negative and eGFP-positive neurons, as summarized in Figure 2c. These data were analyzed with a $t$-test (unpaired, two-tailed), which revealed a significant effect of Q582E expression $\left(t_{13}=2.907, p<0.012\right)$. It is important to emphasize that rectification index differences between eGFP- and eGFP+ cells were found despite the fact that these cells were frequently located close to each other, making it unlikely that rectification index differences arose from tissue damage imposed by virus injection. Together, 


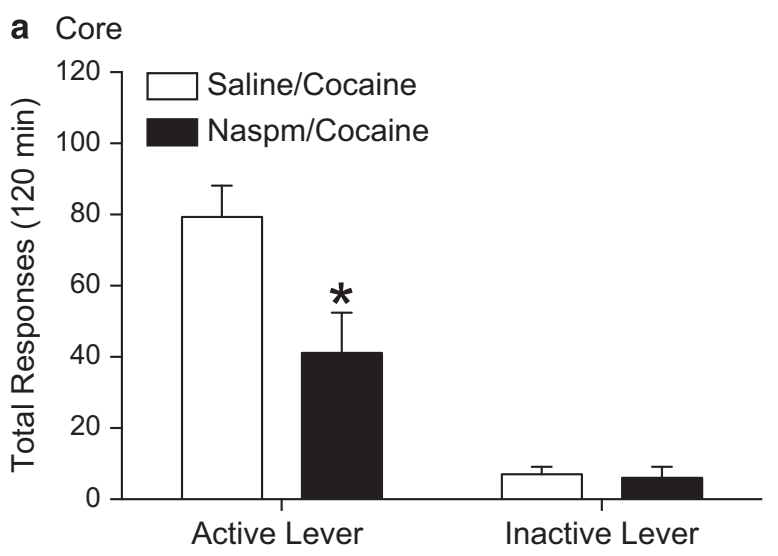

b Shell

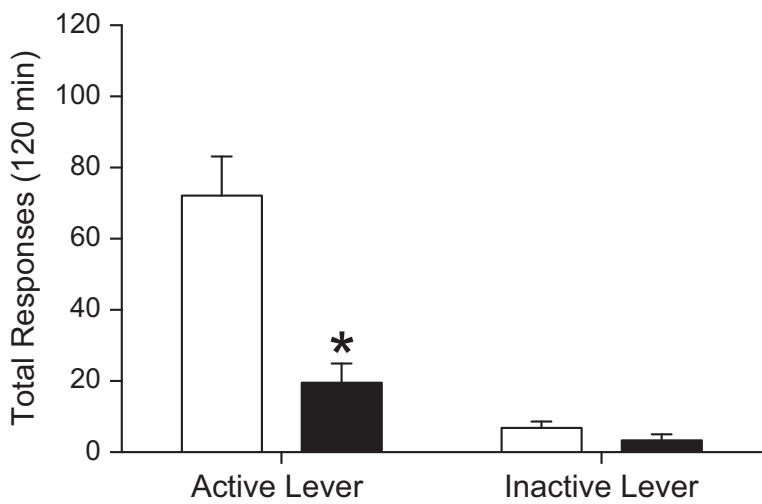

c DL Striatum

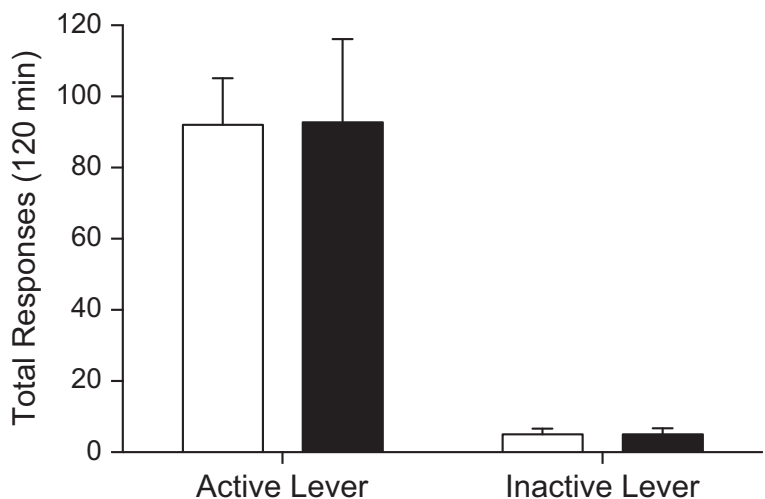

d Core Placements

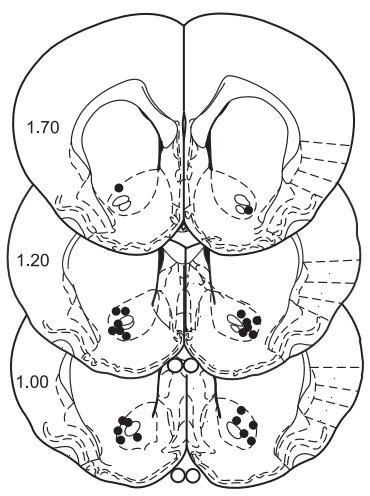

e Shell Placements

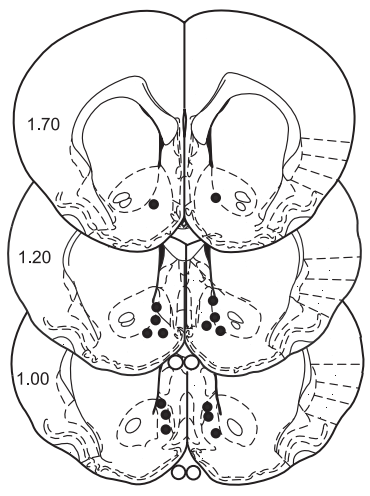

f DL Striatum Placements

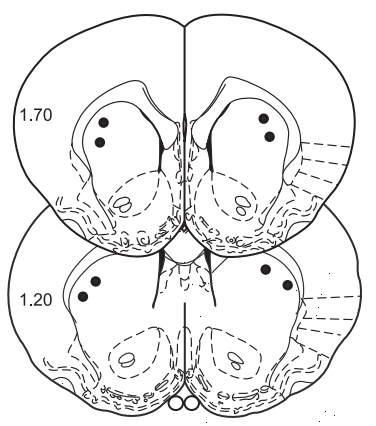

Figure I Microinfusion of the CP-AMPAR antagonist Naspm into the accumbens core or shell, but not the DL striatum, attenuates cocaine priminginduced reinstatement. Total active and inactive lever responding (mean \pm SEM) following microinfusions of saline or Naspm (40 $\mu$ g/side) into the accumbens core (a), accumbens shell (b), or dorsal lateral striatum (c) 10 minutes prior to a systemic injection of cocaine (I 0 mg/kg, i.p.). Note a significant effect of Naspm when administered into the core or shell but not the DL striatum. The asterisks represent significant differences between the saline and Naspm treatments $(p<0.05)$. Cannula placements in the core, shell, and $D L$ striatum are depicted in panels $(d-f)$, respectively. Number of rats per experiment: core $=12$, shell $=8$, DL striatum $=4$.

these data suggest that Q582E attenuates the overall strength of AMPAR-mediated signaling in the nucleus accumbens and increases the contribution of non-rectifying CI-AMPARs to eEPSCs.

Also included in Figure 2 is a comparison of the rectification indices of untreated animals as well as rats exposed to HSV eGFP or HSV GluA1-WT. A one-way ANOVA indicated no significant differences among these groups. These results indicate that eGFP alone likely does not contribute to the observed differences between HSV GluAQ582E eGFP+ and eGFP - cells. There are a number of reasons that may account for the lack of effect of HSVGluA1-WT on rectification. For example, it is very likely that many of the overexpressed GluA1 subunits assembled with GluA2 subunits resulted in an increase in the number of synaptic AMPARs but have no effect on rectification if the ratio of GluA2-containing to GluA2-lacking AMPARs were preserved. 
Table I Effects of Naspm, 'Pore Dead' GluAI-Q582E and miSAP97 Administered into the Core or the Shell on the Reinstatement of Sucrose Seeking

\begin{tabular}{|c|c|c|c|c|}
\hline Treatment & $\mathbf{N}$ & Region administered & Reinstatement: active lever responding & Statistics \\
\hline Saline & 5 & Core & $85.80 \pm 14.10$ & $t_{8}=3.327, p<0.0104$ \\
\hline Naspm & 5 & Core & $28.60 \pm 9.826$ & \\
\hline Saline & 8 & Shell & $77.5 \pm 13.19$ & $t_{14}=0.2291, p<0.8221$ \\
\hline Naspm & 8 & Shell & $81.25 \pm 9.689$ & \\
\hline HSV eGFP & 6 & Core & $77.67 \pm 16.64$ & $t_{10}=0.4970, p<0.6299$ \\
\hline HSV GluAI-Q582E & 6 & Core & $89.83 \pm 17.96$ & \\
\hline HSV eGFP & 6 & Shell & $117.0 \pm 24.46$ & $t_{9}=0.2370, p<0.8180$ \\
\hline HSV GluAI-Q582E & 5 & Shell & $125.2 \pm 23.93$ & \\
\hline HSV eGFP & 6 & Shell & $117.0 \pm 36.88$ & $t_{10}=0.7485, p<0.47 \mid 4$ \\
\hline HSV miSAP97 & 6 & Shell & $158.0 \pm 40.5$ & \\
\hline
\end{tabular}

The active lever responding is expressed as mean \pm SEM. Note that intra-core Napsm significantly decreased sucrose seeking relative to control.

Although rectification index of AMPAR-mediated eEPSCs is a widely used measure of CP-AMPAR content, AMPAR rectification also may depend on other factors such as receptor interactions with chaperone proteins (Soto et al, 2007). This distinction can be addressed by examining the magnitude of Naspm effect on eEPSC amplitude. As Naspm was not used in our electrophysiology experiments, we cannot exclude that factors other than virus-mediated reduction of GluA1-containing receptor signaling are responsible for changes in rectification observed in animals administered HSV GluA-Q582E.

Next, we examined the effect of HSV GluA1-Q582E administered into the caudal lateral core or the caudal medial shell on the reinstatement of cocaine seeking. As summarized in the experimental design outlined in Figure 3a the first reinstatement session occurred 3 days after the virus microinjection (HSV eGFP or HSV GluA1-Q582E), which is when HSV expression peaks (see Figure $3 \mathrm{~b}$ ). Total active and inactive lever responding during the first reinstatement session for animals administered viruses into the core or shell are depicted in Figure $3 c$ and d, respectively (the DL striatum was not examined due to the negative Naspm results summarized previously). Reinstatement was prompted by administration of $10 \mathrm{mg} / \mathrm{kg}$ cocaine (i.p.). These data were analyzed with separate mixed factors ANOVAs with virus as the between-subjects factor and lever and the within subjects factor. Analysis of the core data at Reinstatement $1(n=8-9$, Figure $3 c)$ showed significant main effects of virus $\left(F_{1,15}=9.629, p<0.0073\right)$ and lever $\left(F_{1,15}=42.11, p<0.0001\right)$ as well as a significant virus $\times$ lever interaction $\left(F_{1,15}=10.72, p=0.0051\right)$. Subsequent pairwise analyses revealed a significant difference between virus treatments for active lever responses (Bonferroni, $p<0.05$ ). Analysis of the shell data at Reinstatement 1 (control $n=8$, Pore Dead GluA $n=13$, Figure $3 \mathrm{~d}$ ) revealed significant main effects of virus $\left(F_{1,19}=30.02, p<0.0019\right)$ and lever $\left(F_{1,19}=30.51, p<0.0001\right)$ as well as a significant virus $\times$ lever interaction $\left(F_{1,19}=10.72, p<0.0039\right)$. Subsequent pairwise analyses showed a significant difference between active lever virus effects (Bonferroni, $p<0.05$ ). Seven days after virus administration, when the second reinstatement session occurred, eGFP expression was negligible (see Figure 3e).
Separate ANOVAs of the caudal lateral core (Figure 3f) and caudal medial shell (Figure 3g) reinstatement data on Day 7 revealed only significant main effects of lever. Representative microinjection locations are depicted for the core and shell as insets of Figure $3 \mathrm{f}$ and g, respectively. These data indicate that when the 'pore dead' GluA1-Q582E virus was active (at Reinstatement 1) in either the caudal lateral core or the caudal medial shell reinstatement was suppressed. When the GluA1-Q582E virus in the core and shell was dormant (at Reinstatement 2) the level of cocaine reinstatement returned to control levels.

Sucrose reinstatement also was assessed after virus administration in a separate cohort of animals. The data, which are summarized in Table 1 , indicated no significant differences between HSV GFP and HSV GluA1-Q582E active lever responding 3 days following virus administration into either the core or shell.

\section{Over-Expression of GluA1 Subunits in Shell, but not the Core, Promotes Cocaine Seeking}

In these experiments, HSV eGFP or HSV GluA1-WT were microinjected into the caudal lateral core or caudal medial shell using the same paradigm as depicted in Figure 3 with the exception that a subthreshold dose of cocaine $(5 \mathrm{mg} / \mathrm{kg}$, i.p.) was used in the reinstatement sessions. The statistical analyses were the same as used in Figure 3. HSV GluA1-WT has been used previously in addiction-related experiments (Carlezon et al, 1997; Choi et al, 2011) and was shown to increase AMPAR rectification index in the ventral tegmental area (Choi et al, 2011). When the virus was maximally active (ie, Reinstatement 1), the analysis of the core reinstatement data $(n=7-8)$ indicated no significant main effects or interaction (see Figure 4a). For the shell, analysis of the Reinstatement 1 data $(n=8-9)$ indicated a significant main effect of treatment $\left(F_{1,15}=13.97 p<0.002\right)$, a significant main effect of lever $\left(F_{1,15}=46.25 p<0.0001\right)$, and a significant treatment $\times$ lever interaction $\left(F_{1,15}=8.452 p<0.0108\right)$. Post hoc tests revealed a significant active lever difference between treatments (Bonferroni, $p<0.05$, Figure $4 \mathrm{~b}$ ). For the second reinstatement test, when the virus was dormant, the core data revealed no significant main effects or interaction 
(see Figure 4c). Analysis of the Reinstatement 2 data when the virus was administered into the shell showed a significant main effect of lever $\left(F_{1,14}=8.446 p<0.0115\right)$, but no significant main effect of treatment and no significant interaction (see Figure 4d). Representative microinjection locations are depicted for the core and shell as insets of Figure $4 \mathrm{c}$ and $\mathrm{d}$, respectively. These data indicate that a normally subthreshold dose of cocaine induced cocaine seeking when wild-type GluA1 subunits are overexpressed in the medial accumbens shell. There was a substantial, although not statistically significant, decrease in active lever responding on Reinstatement 1 when HSV GluA1-WT was

a
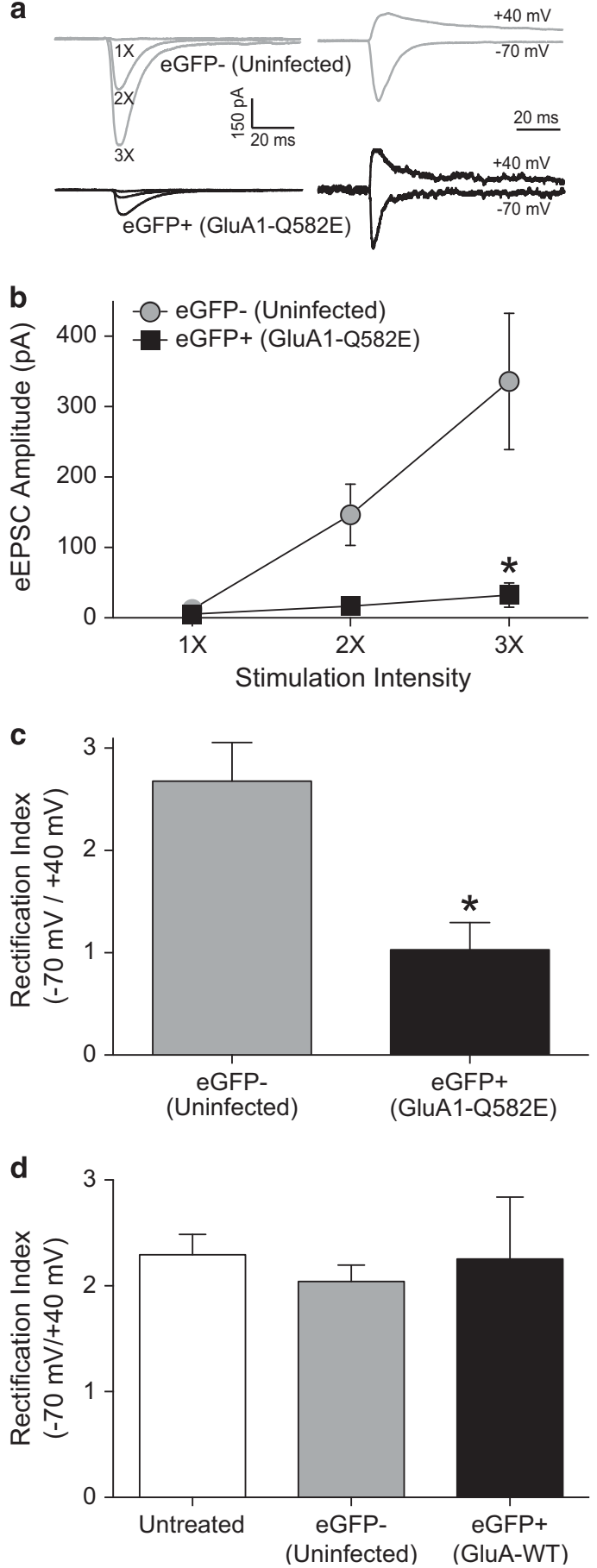

administered into the caudal lateral core, which is noteworthy as HSV GluA1-WT administered more rostrally in the core attenuates cocaine reinstatement (Bachtell et al, 2008).

\section{Inhibiting the Interaction between $4.1 \mathrm{~N}$ and GluA1 in the Shell has no Effect on Cocaine Seeking}

The next experiment examined potential mechanisms underlying the role of GluA1 subunits in the reinstatement of cocaine seeking. As the most consistent results of the previously described experiments were obtained with medial shell manipulations, we focused our attention on this accumbal subregion. We first tested the virus in drug-naive rats and confirmed that eGFP expression in the nucleus accumbens peaked 3 days following administration (see Figure 5a) and was dormant 7 days after microinjection (data not shown). As shown in Figure 5b, $4.1 \mathrm{~N}$ protein expression (native $4.1 \mathrm{~N}$ plus $4.1 \mathrm{~N}-\mathrm{CTD}$ ) was significantly increased 3 days after HSV 4.1N-CTD $\left(t_{18}=2.694, p<0.0148\right)$. Analysis of the reinstatement data revealed only significant main effects of lever responding at Reinstatement 1 $\left(\mathrm{F}_{1,19}=48.02, p<0.0001\right.$, Figure $\left.5 \mathrm{c}\right)$ and Reinstatement 2 $\left(\mathrm{F}_{1,10}=20.37 p=0.0011\right.$, Figure $\left.5 \mathrm{~d}\right)$. There were 5-13 subjects per treatment. Representative microinjection locations in the accumbens shell are shown in the inset of Figure $5 \mathrm{~d}$. These results show that overexpression of $4.1 \mathrm{~N}$ CTD in the medial accumbens shell had no influence on the reinstatement of cocaine seeking.

\section{Reduced Expression of SAP97 in the Accumbens Shell Attenuates Cocaine Priming-Induced Reinstatement}

The experimental design, shown in Figure 6a, was slightly different in this experiment as reinstatement was assessed 4 and 8 days after virus administration. HSV-miSAP97 was initially tested in drug-naive rats. With this virus, the peak effect was observed 4 days after administration of HSV miSAP97 into the nucleus accumbens (see Figure 6b). Knockdown of SAP97 protein by overexpression of miSAP97 was assessed via western blot 2 days following virus

Figure 2 The overexpression of 'pore dead' GluAI-Q582E in accumbens shell MSNs attenuates synaptic strength and decreases inward rectification of AMPAR eEPSCs. (a) Left, representative eEPSC traces at multiples of minimal stimulation intensity in neurons expressing GluAIQ582E (eGFP+) relative to those not expressing eGFP (eGFP - ) recorded from the same slice. Right, representative eEPSC traces at $+40 \mathrm{mV}$ and $-70 \mathrm{mV}$ for eGFP+ and eGFP - neurons, used for rectification index analyses. For ease of visualization, stimulus artifacts were removed and the amplitudes were normalized to the $-70 \mathrm{mV}$ eEPSC in eGFP-neuron. (b) The input-output relationship of AMPAR eEPSCS illustrates decreased synaptic strength in MSNs expressing GluAI-Q582E ( $n=6$ cells from four animals) for peak eEPSC amplitude compared with non-GFP controls $(n=12$ cells from six animals) at $3 \times$ stimulation. (c) Inward rectification of AMPA eEPSCs is more prominent in eGFP - than in eGFP+ cells (ie, peak current is smaller at $+40 \mathrm{mV}$ relative to $-70 \mathrm{mV}$ ). (d) Inward rectification is similar between cells from naive animals, not exposed to virus injections (untreated), cells that were not transduced by GluAI-WT injections (eGFP - ), and cells overexpressing GluAI-WT (eGFP+). Untreated, nine cells from two animals; eGFP - , six cells from two animals, eGFP+, five cells from one animal. 

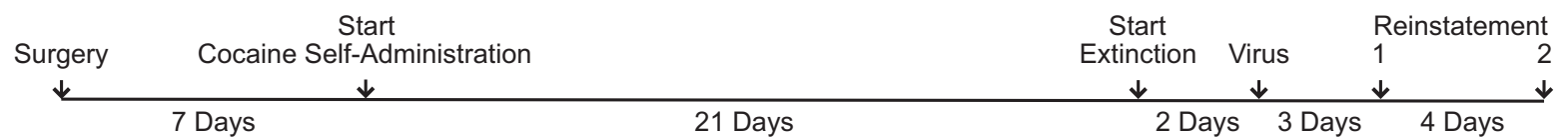
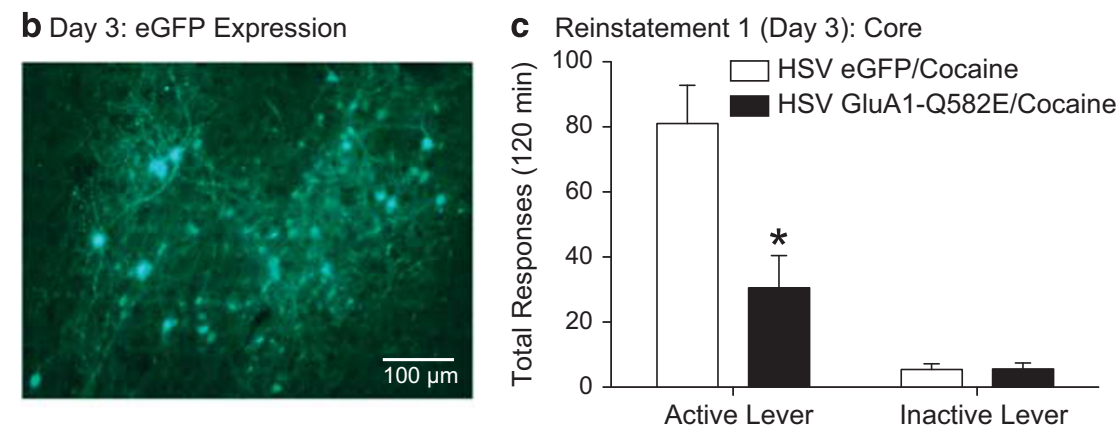

e Day 7: eGFP Expression
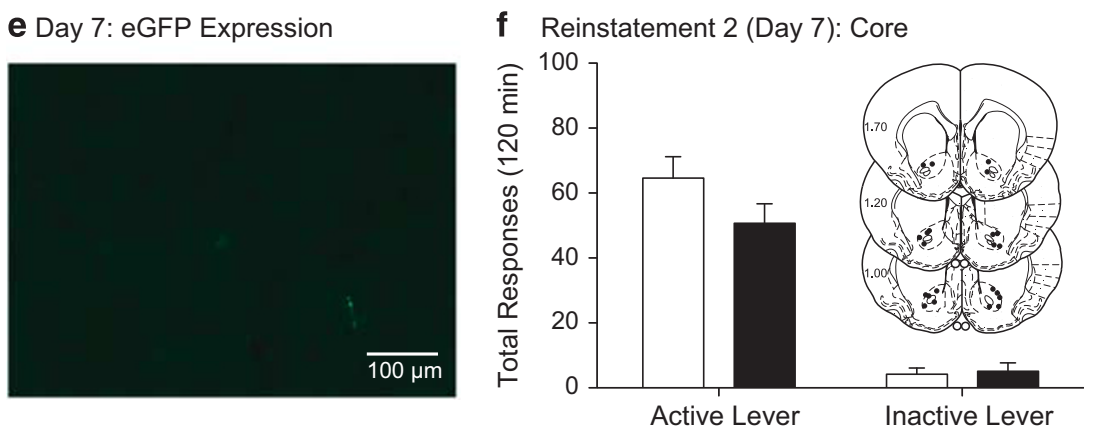

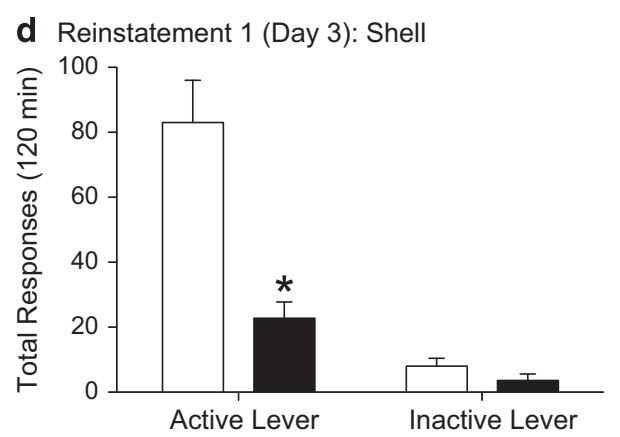

g Reinstatement 2 (Day 7): Shell

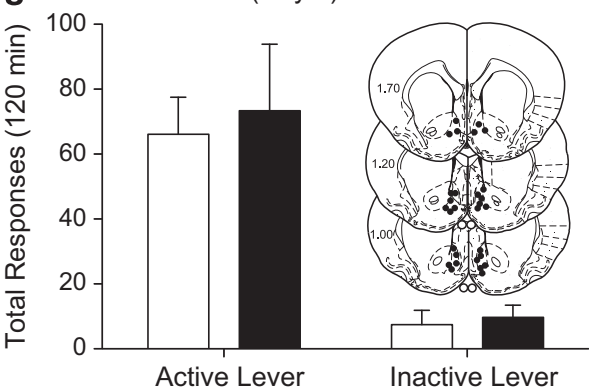

Figure 3 Overexpression of 'pore dead' GluAI-Q582E in the nucleus accumbens core or shell reversibly attenuated cocaine priming-induced reinstatement. (a) Schematic of experimental paradigm. (b) Representative image of peak eGFP fluorescence in the nucleus accumbens 3 days following HSV GluA I-Q582E administration. Total active and inactive lever responding (mean \pm SEM) 3 days after virus microinjection into the core or shell are shown in panels $c$ and d, respectively. Note the significant attenuation of cocaine reinstatement when GluAI-Q-582E was overexpressed in the core or shell. The asterisks represent significant differences between the HSV eGFP and HSV GluAI-Q582E treatments $(p<0.05)$. (e) Representative image of the relative absence of eGFP expression in the nucleus accumbens 7 days following HSV GluAI-Q582E administration. Total active and inactive responding (mean \pm SEM) 7 days following virus administration into the core or shell are shown in panels $f$ and g, respectively. Note that the active lever responding does not differ between treatments. The insets in panels $\mathrm{f}$ and $\mathrm{g}$ depict cannula placements for the core and shell microinjections, respectively. There were $8-9$ rats per treatment.

administration onto cultured hippocampal neurons. Analysis of these data (one-way ANOVA) revealed a significant main effect $\left(F_{2,9}=60.36, p<0.0001\right)$. Subsequent post hoc comparisons (Dunnett's) indicated that SAP97 miRNA significantly decreased SAP97 expression relative to control $(p<0.05)$, whereas the miRNA with a scrambled sequence had no significant effect (see Figure 6c). Analysis of the Reinstatement 1 data ( $n=9$ per treatment) revealed significant main effects of treatment $\left(F_{1,16}=8.225, p<0.0112\right)$ and lever $\left(F_{1,16}=57.19, \quad p<0.0001\right)$ and a significant virus $\times$ lever interaction $\left(F_{1,16}=7.107, p<0.0169\right)$. Post hoc tests indicated a significant active lever difference between treatments (Bonferroni, $p<0.05$, Figure $6 \mathrm{~d}$ ). The virus was dormant 7 days after microinjection. Analysis of the second reinstatement session showed only a significant main effect of lever $\left(F_{1,11}=90.56, p<0.0001\right)$ with no other significant main effect or interaction (see Figure 6e). Representative microinjection locations in the accumbens shell are shown in the inset of Figure 6e. The reinstatement of sucrose seeking also was assessed. HSV miSAP97 had no effect on sucrose seeking (see Table 1). These findings indicate that SAP97 has an important role in the reinstatement of cocaine seeking.

\section{DISCUSSION}

The current results indicate that inhibition of CP-AMPARs in the nucleus accumbens blocks the reinstatement of cocaine seeking. This was demonstrated both pharmacologically and by overexpressing a 'pore dead' GluA1 subunit in the nucleus accumbens. Not only are CP-AMPARs assembled with GluA1 required for cocaine reinstatement, they appear to be sufficient for its expression. Thus, administration of a subthreshold cocaine dose reinstated cocaine seeking when GluAl subunits were overexpressed in the nucleus accumbens. Although the precise role of $\mathrm{CP}$ AMPARs in cocaine-induced changes in accumbens excitatory synaptic transmission needs to be explored in greater detail, our observations indicate that SAP97 is critically involved in this process.

\section{CP-AMPARs and Cocaine Reinstatement}

The present results revealed that administration of the $\mathrm{CP}$ AMPAR antagonist, Naspm, into the nucleus accumbens attenuated the reinstatement of cocaine seeking. In the nucleus accumbens, CP-AMPARs are predominantly GluA1 
a Reinstatement 1 (Day 3): Core

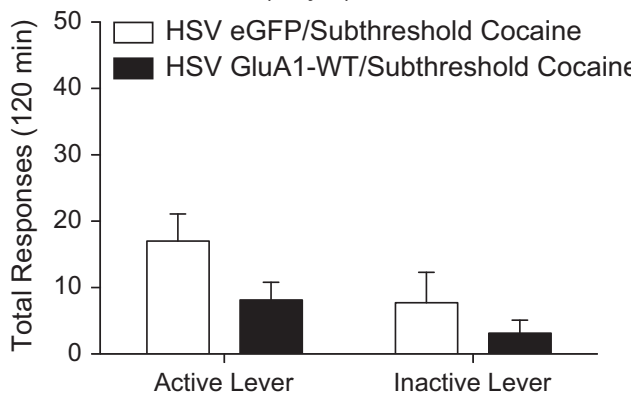

C Reinstatement 2 (Day 7): Core

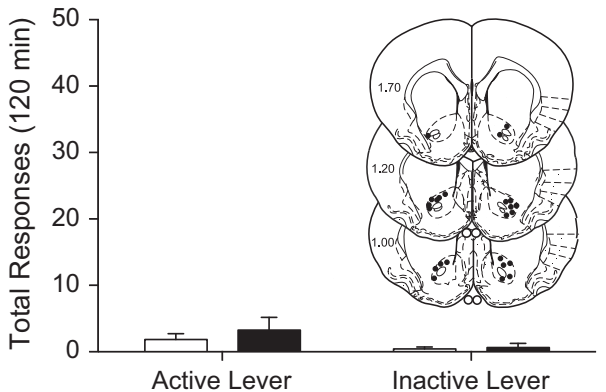

b Reinstatement 1 (Day 3): Shell

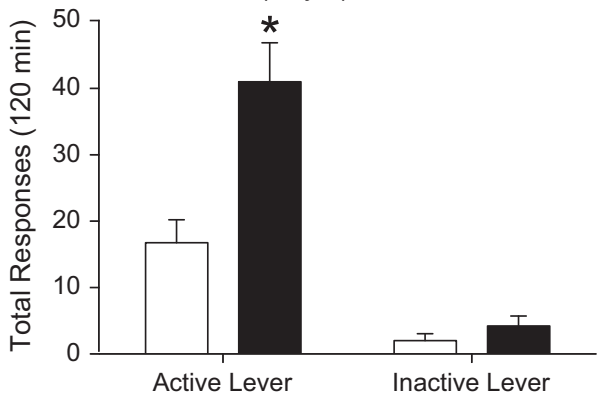

d Reinstatement 2 (Day 7): Shell

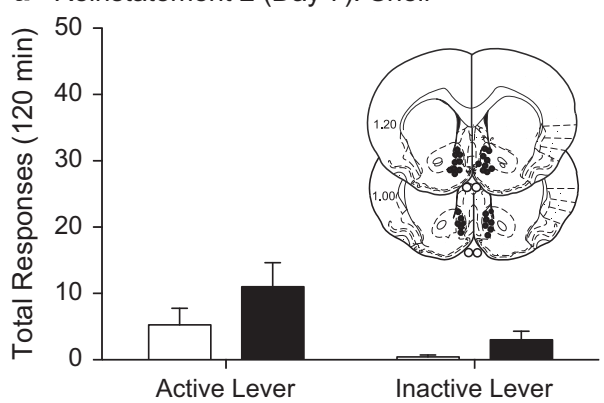

Figure 4 Overexpression of GluAI-WT in the nucleus accumbens shell, but not the core, transiently promotes cocaine-seeking behavior. Total active and inactive lever responding (mean \pm SEM) 3 days following the intra-core or intra-shell microinjection of HSV GFP or HSV GluAI-WT (when expression is maximal) are shown in panels a and b, respectively. Note the robust reinstatement response to a subthreshold dose (5 mg/kg, i.p.) of cocaine only when GluA I subunits are overexpressed in the shell. (b) The asterisk represents a significant difference between the HSV eGFP and GluAI-WT treatments ( $p<0.05)$. Total active and inactive lever responding (mean \pm SEM) I week following intra-core or intra-shell administration of HSV GFP or HSV GluA I-WT, when the viruses are dormant, are depicted in panels $\mathrm{c}$ and d, respectively. Note that a subthreshold injection of cocaine $(5 \mathrm{mg} / \mathrm{kg}$, i.p.) failed to produce reinstatement in either viral treatment condition in either the core or shell subregion of the nucleus accumbens. There were 7-9 rats per treatment.

homomers or GluA1/GluA3 heteromers (Boudreau et al, 2007; Reimers et al, 2011). It was previously shown that administration of Naspm into the accumbens core blocked 'incubated' cocaine seeking (Conrad et al, 2008). Consistent with this finding, we showed that Naspm administered into either subregion of the accumbens, the core or the shell, attenuated the reinstatement of cocaine seeking induced by a cocaine priming injection. Administration of Naspm into the core also impaired sucrose seeking, suggesting that the core has a broader role in the modulation of reinforced behaviors, as noted previously (Bari and Pierce, 2005). Naspm administered into the DL striatum had no effect on cocaine seeking. Previous work indicated no changes in GluA1 phosphorylation in the DL striatum following cocaine selfadministration (White et al, 2013). Collectively, these results indicated that GluA1-containing AMPARs in the accumbens core and shell contribute to the reinstatement of cocaine seeking during extinction, with the effects in the shell being relatively cocaine-specific.

In rats, CP-AMPARs in the nucleus accumbens typically account for $<10 \%$ of eEPSC amplitude (Conrad et al, 2008). However, extended-access cocaine self-administration followed by protracted forced abstinence increased synaptic expression of CP-AMPARs in the nucleus accumbens such that these AMPARs were responsible for $\sim 30 \%$ of eEPSC amplitude (Conrad et al, 2008; Mameli et al, 2009). Extended-access cocaine self-administration enhanced the functional influence of CP-AMPARs in both the accumbens core (Ferrario et al, 2011; McCutcheon et al, 2011a, c) and shell (Mameli et al, 2009; McCutcheon et al, 2011c). In contrast, the ability of Naspm to attenuate eEPSCs in the accumbens core during abstinence following short-access cocaine self-administration did not differ from saline-treated controls (Purgianto et al, 2013). It is questionable, therefore, that blocking CP-AMPARs present in the nucleus accumbens prior to the reinstatement session is responsible for the ability of Naspm to attenuate the reinstatement of cocaine seeking using the current short-access cocaine selfadministration paradigm. An important difference between the current work and previous studies of extended- and short-access cocaine self-administration is that our experiments included the extinction of cocaine seeking. However, we failed to observe differences in the inward rectification of AMPAR eEPSCs between animals that did or did not undergo extinction following short-access cocaine selfadministration. It seems most likely, therefore, that the reinstatement of cocaine seeking using the current paradigm is associated with transient increases in surface CP-AMPAR accumulation in the nucleus accumbens, which is consistent with previous work (Anderson et al, 2008; Schierberl et al, 2011).

\section{GluA1-Containing AMPARs and Cocaine Reinstatement}

As noted previously, there is extensive evidence that cocaine self-administration influences nucleus accumbens GluA1containing AMPARs. In the present experiments, overexpressing pore dead GluA1-Q582E in either the caudal 
a Day 3: eGFP Expression

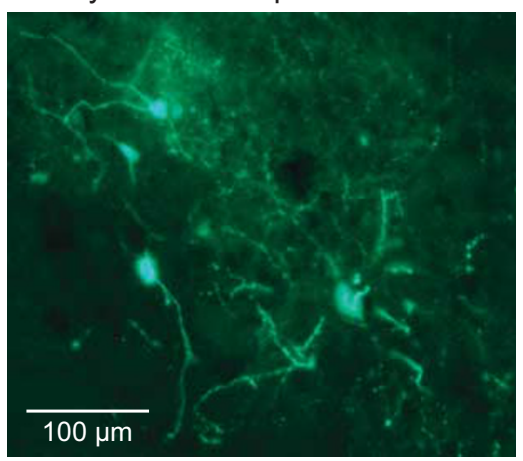

b Day 3: 4.1N Over-Expression

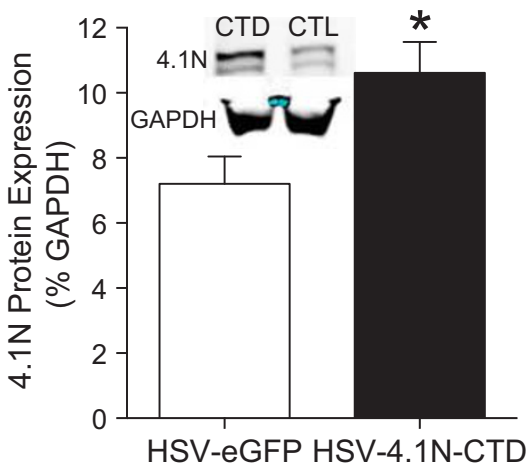

c Reinstatement 1: Shell

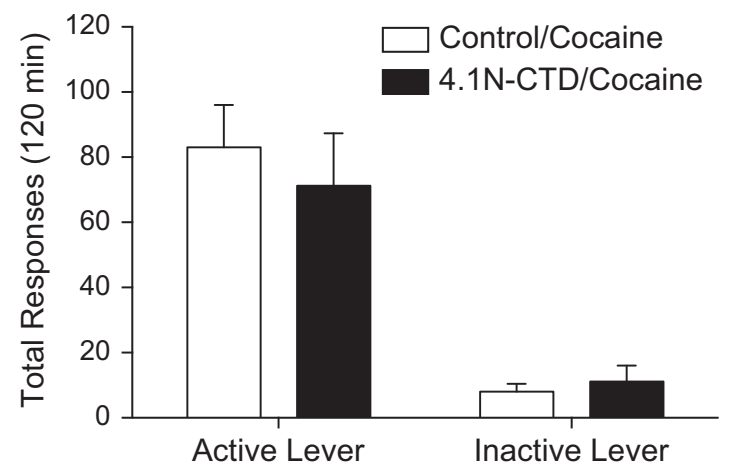

d Reinstatement 2: Shell

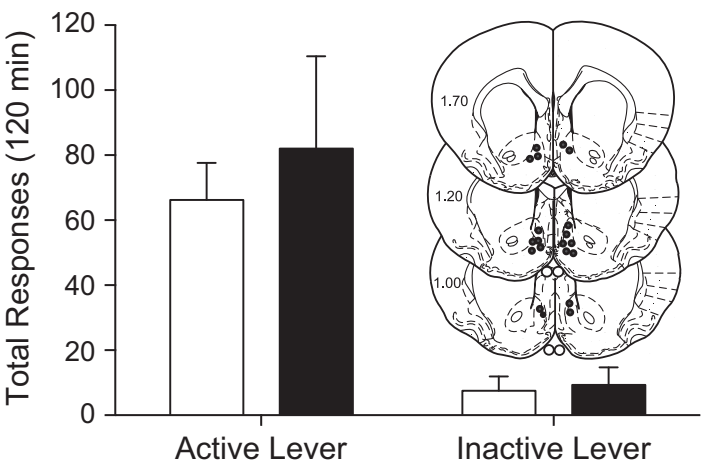

Figure 5 Viral-mediated overexpression of 4.IN-CTD in the nucleus accumbens shell has no effect on the reinstatement of cocaine seeking. (a) Representative image of peak eGFP fluorescence in the nucleus accumbens 3 days following HSV 4.IN-CTD infusion. (b) Increases in 4.IN protein expression induced by HSV 4.IN-CTD as assessed with western blot (see inset). Total active and inactive lever responding (mean \pm SEM) 3 days or I week following intra-shell microinfusion of HSV eGFP or HSV 4.IN-CTD is shown in panels $\mathrm{c}$ and $\mathrm{d}$, respectively. Note that the active lever responding to a systemic injection of cocaine ( $10 \mathrm{mg} / \mathrm{kg}$, i.p.) does not differ between treatments at either time point. The inset in panel d depicts cannula placements for all shell microinjections. There were 5-13 rats per treatment.

lateral core or caudal medial shell subregion of the nucleus accumbens attenuated cocaine priming-induced reinstatement, without altering sucrose-seeking behavior. Correspondingly, the present results showed that viral-mediated overexpression of wild-type GluA1 in the shell facilitated drug seeking when combined with a normally subthreshold dose of cocaine. Taken together, these findings suggest that synaptic incorporation of accumbens GluA1-containing AMPARs, some of which may form CP-AMPARs, facilitates cocaine seeking. However, previous work showed that overexpression of 'pore dead' GluA1 in the accumbens core actually facilitated the reinstatement of cocaine seeking (Bachtell et al, 2008). There are several methodological differences between the previous and current studies, but perhaps most important are the respective delineations of the accumbens core. It has been shown that the disrupting AMPAR transmission in the rostral accumbens core promotes appetitive behaviors, with this effect reversing when AMPAR antagonists are administered more caudally (Reynolds and Berridge, 2008). Similarly, impairing GluA1mediated AMPAR transmission in the caudal core in the present experiments impaired cocaine seeking, whereas this identical manipulation in the rostral core enhanced cocaine reinstatement (Bachtell et al, 2008). These results highlight critical differences in the role GluA1-mediated AMPARs in subregions of the accumbens core.
Approximately 95\% of nucleus accumbens neurons are GABAergic medium spiny outputs that are differentiated through their expression of D1 and D2 dopamine receptors (Lobo and Nestler, 2011). Accumulating evidence indicates that activation of D1 dopamine receptors (D1DRs) in the nucleus accumbens shell promotes cocaine seeking by influencing transmission through GluA1-containing AMPARs. Thus, stimulation of D1DRs in the nucleus accumbens shell reinstates cocaine seeking, in part, by serially activating L-type calcium channels and calcium/calmodulin-dependent protein kinase II (CaMKII) (Anderson et al, 2008; Schmidt et al, 2006a; Schmidt and Pierce, 2006d). Cocaine reinstatement also was associated with D1DR-dependent increases in GluA1-pSer831, a CaMKII phosphorylation site, as well as increased cell surface expression of GluA1-containing AMPARs in the shell (Anderson et al, 2008). Notably, administration of a D1DR agonist into the medial, but not the lateral, core reinstated cocaine seeking (Bachtell et al, 2005; Schmidt et al, 2006a), which emphasizes medial-lateral in addition to rostral-caudal (see above) differences in accumbens modulation of drug seeking. Viral-mediated expression of GluA1-Q582E in the medial core blocked intra-accumbal D1DR agonist-induced reinstatement of cocaine seeking (Hobson et al, 2013). Taken together, these results indicate that the reinstatement of cocaine seeking is facilitated by enhanced transmission through GluA1-containing AMPARs in D1DR-expressing neurons 
a

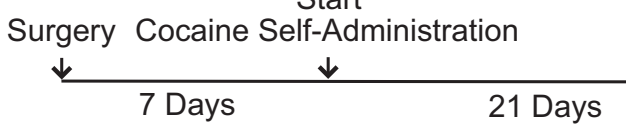

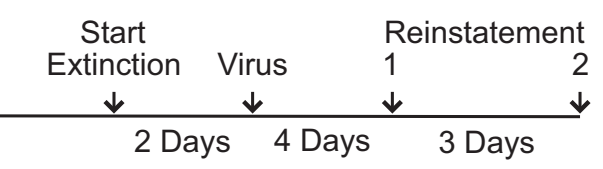

b Day 4: eGFP Expression
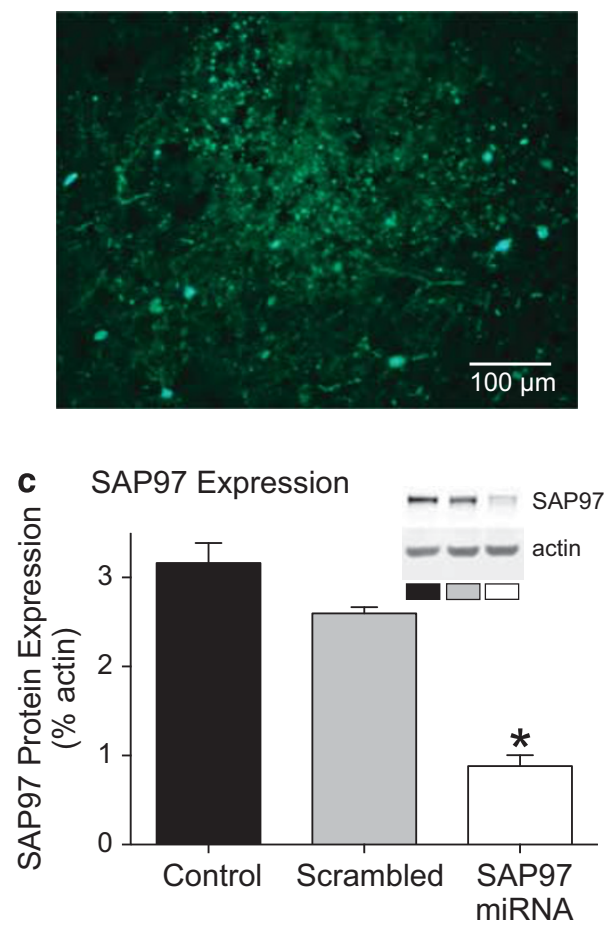

d Reinstatement 1: Shell

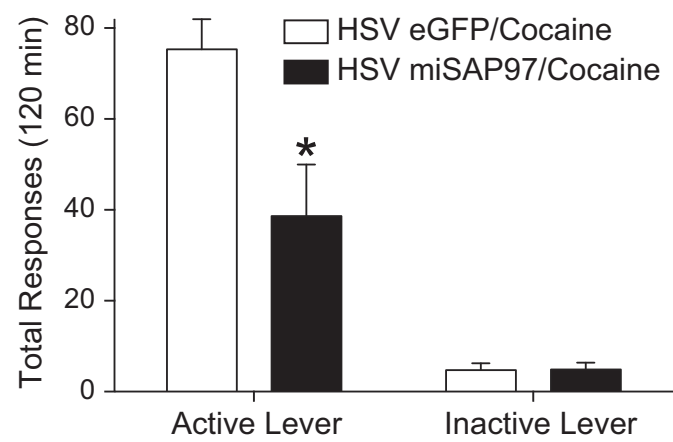

e Reinstatement 2: Shell

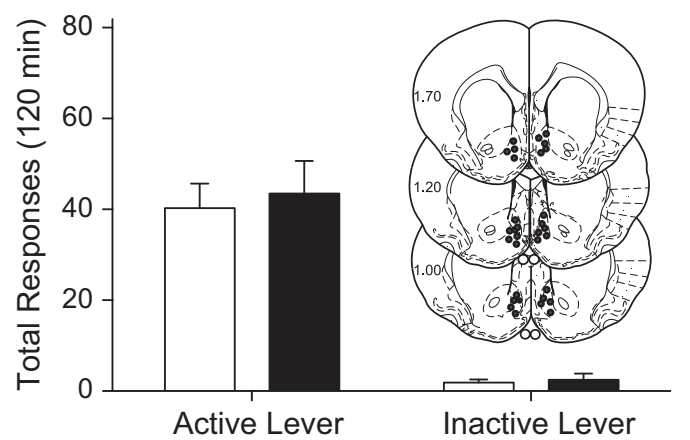

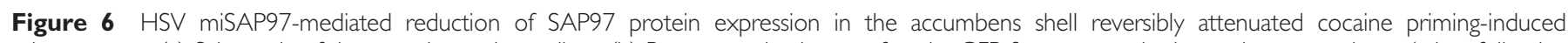

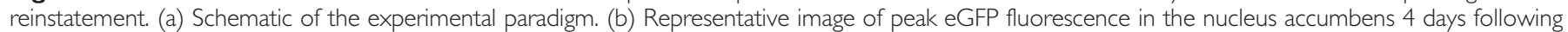

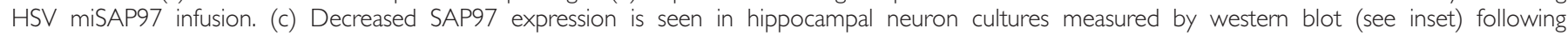

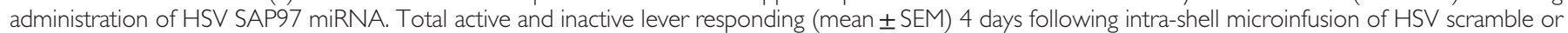

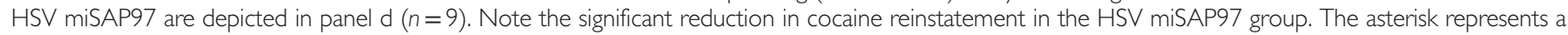

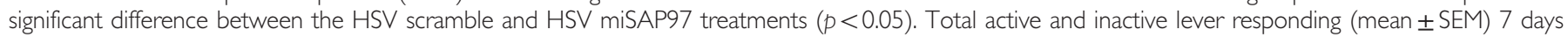

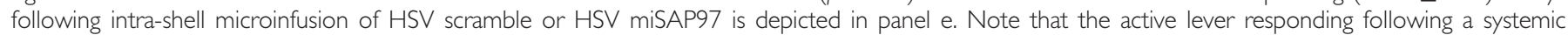
injection of cocaine (10 mg/kg, i.p.) did not differ between treatments. The inset in panel e depicts cannual placements for all shell microinjections.

in the medial core and medial shell of the nucleus accumbens.

Similar to D1DR agonists, administration of D2 dopamine receptor (D2DR) agonists into the medial core or medial shell promoted the reinstatement of cocaine seeking (Bachtell et al, 2005; Schmidt et al, 2006a; Schmidt and Pierce, 2006d). D2DRs signal through G-proteins including G $\beta \gamma$ and Gi. Recent evidence indicates that D2DR-induced activation of $\mathrm{G} \beta \gamma$-PLC- $\mathrm{PIP}_{2}$-PKC promotes cocaine seeking by internalizing GluA2-containing AMPARs, thereby decreasing overall AMPAR-mediated synaptic strength in D2DRexpressing neurons (Famous et al, 2008; Schmidt et al, 2013, 2014; Wiggins et al, 2011). Collectively, these results indicate that enhanced AMPAR-mediated neurotransmission in D2DR-containing accumbens output neurons suppresses cocaine reinstatement. Consistent with these results, strengthening of glutamatergic inputs onto D2DRcontaining accumbens neurons restrains cocaine selfadministration (Bock et al, 2013). In contrast, as noted above, increased AMPA transmission in accumbens neurons that express D1DRs promotes cocaine seeking. Differential effects of cocaine on the two populations of accumbens output neurons also may help to explain discrepancies in the literature in terms of the precise role of accumbens AMPAR subunits in the reinstatement of cocaine seeking (Anderson et al, 2008; Conrad et al, 2008; Famous et al, 2008; Hobson et al, 2013; Ping et al, 2008; Sutton et al, 2003). That said, studies have shown increased AMPAR rectification in the nucleus accumbens following cocaine self-administration when neurons were selected in an unbiased manner, which suggests increased accumulation of CPAMPARs in both populations of accumbens efferent neurons (Ma et al, 2014; McCutcheon et al, 2011c; Scheyer et al, 2014).

\section{GluA1 Accessory Proteins and Cocaine Reinstatement}

The current results showed that reducing the abundance of SAP97 suppressed cocaine priming-induced reinstatement of drug seeking. However, impairing the interaction between $4.1 \mathrm{~N}$ and GluA1 had no influence on cocaine seeking. This latter effect was somewhat surprising given that $4.1 \mathrm{~N}$ 
interacts with PKC and GluA1 subunits (Lin et al, 2009), both of which contribute to the reinstatement of cocaine seeking (Pierce and Wolf, 2013; Schmidt et al, 2014).

CaMKII, which has a critical role in psychostimulantmediated behavioral plasticity (Anderson et al, 2008; Loweth et al, 2010; Pierce et al, 1998), phosphorylates SAP97 (at Ser39), which promotes the transport of SAP97 to synapses (Mauceri et al, 2004). Initial studies suggested that CaMKII phosphorylated GluA1 (at Ser831) to promote the trafficking of GluA1-containing AMPARs to the cell surface (Malinow and Malenka, 2002). However, it was subsequently shown that this effect was not influenced by mutating the GluA1 Ser831 residue (Hayashi et al, 2000). These results suggested that CaMKII might influence AMPAR trafficking indirectly, perhaps via interactions with accessory proteins such as SAP97. Indeed, impairing the interaction between SAP97 and GluA1 impairs surface insertion of GluA1 (Passafaro et al, 2001) in a CaMKII-dependent manner (Nikandrova et al, 2010; Schluter et al, 2006). Contrary to these findings, a knock-in mouse lacking the final seven GluA1 C-terminal amino acids (the SAP97-binding site) had normal GluA1 synaptic localization, trafficking, and basal synaptic transmission (Kim et al, 2005; Zhou et al, 2008). However, these results may be due to compensation by other MAGUKs, which are functionally redundant (Howard et al, 2010). Interactions between SAP97 and GluA1 also promote dendritic branching in an activity-dependent manner (Jablonski and Kalb, 2013; Zhou et al, 2008). Given that structural plasticity is observed in the nucleus accumbens following exposure to cocaine (Robinson and Kolb, 2004; Shen et al, 2009), it is intriguing to speculate that SAP97GluA1 may have a role in this process.

SAP97 interacts with many other targets in addition to GluA1. For example, CaMKII phosphorylation of SAP97 at Ser232 regulates the synaptic targeting of NMDA receptors containing NR2A subunits (Gardoni et al, 2003; Mauceri et al, 2007). Although there is substantially less evidence for a role of NMDA receptors in cocaine-induced neuronal plasticity relative to AMPARs, there is evidence that repeated cocaine alters NR2A expression in the nucleus accumbens (Ary and Szumlinski, 2007; Ortinski et al, 2013; Schumann and Yaka, 2009). We also recently showed an increase in extrasynaptic NMDA receptor signaling in cocaineexperienced rats (Ortinski et al, 2013).

\section{CONCLUSIONS}

These present results add to the growing literature indicating that increased transmission through GluA1-containing AMPARs, some of which are CP-AMPARs, in both subregions of the nucleus accumbens promotes the reinstatement of cocaine seeking. Moreover, viral-mediated expression of a miRNA, which reduces the expression of the GluA1 chaperone protein, SAP97, attenuated cocaine seeking. These data suggest that the AMPAR accessory protein SAP97 may be a potential novel target for the development of cocaine addiction pharmacotherapies.

\section{FUNDING AND DISCLOSURE}

The authors declare no conflict of interest.

\section{ACKNOWLEDGMENTS}

This work was supported by the following grants from the National Institutes of Health: R01 DA022339 (RCP), K02 DA18678 (RCP), F31 DA31535 (SLW), K01 DA31747 (PIO) and K01 DA030445 (HDS). Dr Pierce is a paid consultant of Perkins Coie, LLP. Dr White is now an AAAS Science/ Technology Policy Fellow paid by the National Institute for Neurological Disorders and Stroke, NIH.

\section{REFERENCES}

Anderson SM, Famous KR, Sadri-Vakili G, Kumaresan V, Schmidt HD, Bass CE et al (2008). CaMKII: a biochemical bridge linking accumbens dopamine and glutamate systems in cocaine seeking. Nat Neurosci 11: 344-353.

Ary AW, Szumlinski KK (2007). Regional differences in the effects of withdrawal from repeated cocaine upon Homer and glutamate receptor expression: a two-species comparison. Brain Res 1184: 295-305.

Bachtell RK, Choi KH, Simmons DL, Falcon E, Monteggia LM, Neve RL et al (2008). Role of GluR1 expression in nucleus accumbens neurons in cocaine sensitization and cocaine-seeking behavior. Eur J Neurosci 27: 2229-2240.

Bachtell RK, Whisler K, Karanian D, Self DW (2005). Effects of intra-nucleus accumbens shell administration of dopamine agonists and antagonists on cocaine-taking and cocaine-seeking behaviors in the rat. Psychopharmacology (Berl) 183: 41-53.

Bari AA, Pierce RC (2005). D1-like and D2 dopamine receptor antagonists administered into the shell subregion of the rat nucleus accumbens decrease cocaine, but not food, reinforcement. Neuroscience 135: 959-968.

Bock R, Shin JH, Kaplan AR, Dobi A, Markey E, Kramer PF et al (2013). Strengthening the accumbal indirect pathway promotes resilience to compulsive cocaine use. Nat Neurosci 16: 632-638.

Boudreau AC, Reimers JM, Milovanovic M, Wolf ME (2007). Cell surface AMPA receptors in the rat nucleus accumbens increase during cocaine withdrawal but internalize after cocaine challenge in association with altered activation of mitogen-activated protein kinases. J Neurosci 27: 10621-10635.

Cai C, Coleman SK, Niemi K, Keinanen K (2002). Selective binding of synapse-associated protein 97 to GluR-A alpha-amino-5hydroxy-3-methyl-4-isoxazole propionate receptor subunit is determined by a novel sequence motif. J Biol Chem 277: 31484-31490.

Carlezon WA Jr, Boundy VA, Haile CN, Lane SB, Kalb RG, Neve $\mathrm{RL}$ et al (1997). Sensitization to morphine induced by viralmediated gene transfer. Science 277: 812-814.

Choi KH, Edwards S, Graham DL, Larson EB, Whisler KN, Simmons D et al (2011). Reinforcement-related regulation of AMPA glutamate receptor subunits in the ventral tegmental area enhances motivation for cocaine. J Neurosci 31: 7927-7937.

Conrad KL, Tseng KY, Uejima JL, Reimers JM, Heng LJ, Shaham Y et al (2008). Formation of accumbens GluR2-lacking AMPA receptors mediates incubation of cocaine craving. Nature 454: $118-121$.

Cull-Candy S, Kelly L, Farrant M (2006). Regulation of $\mathrm{Ca}^{2+}$-permeable AMPA receptors: synaptic plasticity and beyond. Curr Opin Neurobiol 16: 288-297.

Dingledine R, Borges K, Bowie D, Traynelis SF (1999). The glutamate receptor ion channels. Pharmacol Rev 51: 7-61.

Famous KR, Kumaresan V, Sadri-Vakili G, Schmidt HD, Mierke DF, Cha JH et al (2008). Phosphorylation-dependent trafficking of GluR2-containing AMPA receptors in the nucleus accumbens plays a critical role in the reinstatement of cocaine seeking. $J$ Neurosci 28: 11061-11070. 
Ferrario CR, Loweth JA, Milovanovic M, Ford KA, Galinanes GL, Heng LJ et al (2011). Alterations in AMPA receptor subunits and TARPs in the rat nucleus accumbens related to the formation of $\mathrm{Ca}^{2+}$-permeable AMPA receptors during the incubation of cocaine craving. Neuropharmacology 61: 1141-1151.

Fukatsu K, Bannai H, Zhang S, Nakamura H, Inoue T, Mikoshiba K (2004). Lateral diffusion of inositol 1,4,5-trisphosphate receptor type 1 is regulated by actin filaments and $4.1 \mathrm{~N}$ in neuronal dendrites. J Biol Chem 279: 48976-48982.

Gardoni F, Mauceri D, Fiorentini C, Bellone C, Missale C, Cattabeni $\mathrm{F}$ et al (2003). CaMKII-dependent phosphorylation regulates SAP97/NR2A interaction. J Biol Chem 278: 44745-44752.

Hayashi Y, Shi SH, Esteban JA, Piccini A, Poncer JC, Malinow R (2000). Driving AMPA receptors into synapses by LTP and CaMKII: requirement for GluR1 and PDZ domain interaction. Science 287: 2262-2267.

Hobson BD, O'Neill CE, Levis SC, Monteggia LM, Neve RL, Self DW et al (2013). Adenosine A and dopamine D receptor regulation of AMPA receptor phosphorylation and cocaineseeking behavior. Neuropsychopharmacology 38: 1974-1983.

Howard MA, Elias GM, Elias LA, Swat W, Nicoll RA (2010). The role of SAP97 in synaptic glutamate receptor dynamics. Proc Natl Acad Sci USA 107: 3805-3810.

Jablonski AM, Kalb RG (2013). GluA1 promotes the activitydependent development of motor circuitry in the developing segmental spinal cord. Ann N Y Acad Sci 1279: 54-59.

Kim CH, Takamiya K, Petralia RS, Sattler R, Yu S, Zhou W et al (2005). Persistent hippocampal CA1 LTP in mice lacking the C-terminal PDZ ligand of GluR1. Nat Neurosci 8: 985-987.

Lee HK (2012). Ca-permeable AMPA receptors in homeostatic synaptic plasticity. Front Mol Neurosci 5: 17.

Lin DT, Makino Y, Sharma K, Hayashi T, Neve R, Takamiya K et al (2009). Regulation of AMPA receptor extrasynaptic insertion by 4.1N, phosphorylation and palmitoylation. Nat Neurosci 12: 879-887.

Lobo MK, Nestler EJ (2011). The striatal balancing act in drug addiction: distinct roles of direct and indirect pathway medium spiny neurons. Front Neuroanat 5: 41.

Loweth JA, Singer BF, Baker LK, Wilke G, Inamine H, Bubula N et al (2010). Transient overexpression of a- $\mathrm{Ca}^{2+} /$ calmodulindependent protein kinase II in the nucleus accumbens shell enhances behavioral responding to amphetamine. J Neurosci 30: 939-949.

Ma YY, Lee BR, Wang X, Guo C, Liu L, Cui R et al (2014). Bidirectional modulation of incubation of cocaine craving by silent synapse-based remodeling of prefrontal cortex to accumbens projections. Neuron 83: 1453-1467.

Malinow R, Malenka RC (2002). AMPA receptor trafficking and synaptic plasticity. Annu Rev Neurosci 25: 103-126.

Mameli M, Halbout B, Creton C, Engblom D, Parkitna JR, Spanagel $\mathrm{R}$ et al (2009). Cocaine-evoked synaptic plasticity: persistence in the VTA triggers adaptations in the NAc. Nat Neurosci 12: 1036-1041.

Mauceri D, Cattabeni F, Di Luca M, Gardoni F (2004). Calcium/ calmodulin-dependent protein kinase II phosphorylation drives synapse-associated protein 97 into spines. J Biol Chem 279: 23813-23821.

Mauceri D, Gardoni F, Marcello E, Di Luca M (2007). Dual role of CaMKII-dependent SAP97 phosphorylation in mediating trafficking and insertion of NMDA receptor subunit NR2A. J Neurochem 100: 1032-1046.

McCutcheon JE, Loweth JA, Ford KA, Marinelli M, Wolf ME, Tseng KY (2011a). Group I mGluR activation reverses cocaine-induced accumulation of calcium-permeable AMPA receptors in nucleus accumbens synapses via a protein kinase C-dependent mechanism. J Neurosci 31: 14536-14541.

McCutcheon JE, Wang X, Tseng KY, Wolf ME, Marinelli M (2011c). Calcium-permeable AMPA receptors are present in nucleus accumbens synapses after prolonged withdrawal from cocaine self-administration but not experimenter-administered cocaine. J Neurosci 31: 5737-5743.

Nikandrova YA, Jiao Y, Baucum AJ, Tavalin SJ, Colbran RJ (2010). $\mathrm{Ca} 2+/$ calmodulin-dependent protein kinase II binds to and phosphorylates a specific SAP97 splice variant to disrupt association with AKAP79/150 and modulate alpha-amino-3hydroxy-5-methyl-4-isoxazolepropionic acid-type glutamate receptor (AMPAR) activity. J Biol Chem 285: 923-934.

Ortinski PI, Turner JR, Pierce RC (2013). Extrasynaptic targeting of NMDA receptors following D1 dopamine receptor activation and cocaine self-administration. J Neurosci 33: 9451-9461.

Passafaro M, Piech V, Sheng M (2001). Subunit-specific temporal and spatial patterns of AMPA receptor exocytosis in hippocampal neurons. Nat Neurosci 4: 917-926.

Paxinos G, Watson C (1997). The Rat Brain in Stereotaxic Coordinates. Academic Press: New York, NY, USA.

Pierce RC, Quick EA, Reeder DC, Morgan ZR, Kalivas PW (1998). Calcium-mediated second messengers modulate the expression of behavioral sensitization to cocaine. J Pharmacol Exp Ther 286: 1171-1176.

Pierce RC, Wolf ME (2013). Psychostimulant-induced neuroadaptations in nucleusaccumbens AMPA receptor transmission. In: Pierce RC, Kenny PJ (eds). Addiction. Cold Spring Harbor Laboratory Press: Cold Spring Harbor: New York, NY, USA, pp 121-134.

Ping A, Xi J, Prasad BM, Wang MH, Kruzich PJ (2008). Contributions of nucleus accumbens core and shell GluR1 containing AMPA receptors in AMPA- and cocaine-primed reinstatement of cocaine-seeking behavior. Brain Res 1215: 173-182.

Purgianto A, Scheyer AF, Loweth JA, Ford KA, Tseng KY, Wolf ME (2013). Different adaptations in AMPA receptor transmission in the nucleus accumbens after short vs long access cocaine self-administration regimens. Neuropsychopharmacology $\mathbf{3 8}$ 1789-1797.

Reimers JM, Milovanovic M, Wolf ME (2011). Quantitative analysis of AMPA receptor subunit composition in addiction-related brain regions. Brain Res 1367: 223-233.

Reynolds SM, Berridge KC (2008). Emotional environments retune the valence of appetitive versus fearful functions in nucleus accumbens. Nat Neurosci 11: 423-425.

Robinson TE, Kolb B (2004). Structural plasticity associated with exposure to drugs of abuse. Neuropharmacology 47 Suppl 1: 33-46.

Scheyer AF, Wolf ME, Tseng KY (2014). A protein synthesisdependent mechanism sustains calcium-permeable AMPA receptor transmission in nucleus accumbens synapses during withdrawal from cocaine self-administration. J Neurosci 34: 3095-3100.

Schierberl K, Hao J, Tropea TF, Ra S, Giordano TP, Xu Q et al (2011). $\mathrm{Ca}_{\mathrm{v}} 1.2$ L-type $\mathrm{Ca}^{2+}$ channels mediate cocaine-induced GluA1 trafficking in the nucleus accumbens, a long-term adaptation dependent on ventral tegmental area $\mathrm{Ca}_{\mathrm{v}} 1.3$ channels. J Neurosci 31: 13562-13575.

Schluter OM, Xu W, Malenka RC (2006). Alternative N-terminal domains of PSD-95 and SAP97 govern activity-dependent regulation of synaptic AMPA receptor function. Neuron 51: 99-111.

Schmidt HD, Anderson SM, Pierce RC (2006a). Stimulation of D1like or D2 dopamine receptors in the shell, but not the core, of the nucleus accumbens reinstates cocaine-seeking behaviour in the rat. Eur J Neurosci 23: 219-228.

Schmidt HD, Kimmey BA, Arreola AC, Pierce RC (2014). Group I metabotropic glutamate receptor-mediated activation of PKC gamma in the nucleus accumbens core promotes the reinstatement of cocaine seeking. Addict Biol 20: 285-296. 
Schmidt HD, Pierce RC (2006d). Cooperative activation of D1-like and D2-like dopamine receptors in the nucleus accumbens shell is required for the reinstatement of cocaine-seeking behavior in the rat. Neuroscience 142: 451-461.

Schmidt HD, Pierce RC (2010). Cocaine-induced neuroadaptations in glutamate transmission: potential therapeutic targets for craving and addiction. Ann N Y Acad Sci 1187: 35-75.

Schmidt HD, Schassburger RL, Guercio LA, Pierce RC (2013). Stimulation of mGluR5 in the accumbens shell promotes cocaine seeking by activating PKC gamma. J Neuroscience 33: 14160-14169.

Schumann J, Yaka R (2009). Prolonged withdrawal from repeated noncontingent cocaine exposure increases NMDA receptor expression and ERK activity in the nucleus accumbens. J Neurosci 29: 6955-6963.

Shen HW, Toda S, Moussawi K, Bouknight A, Zahm DS, Kalivas PW (2009). Altered dendritic spine plasticity in cocainewithdrawn rats. J Neurosci 29: 2876-2884.

Shen L, Liang F, Walensky LD, Huganir RL (2000). Regulation of AMPA receptor GluR1 subunit surface expression by a 4. 1 N-linked actin cytoskeletal association. J Neurosci 20: 7932-7940.

Soto D, Coombs ID, Kelly L, Farrant M, Cull-Candy SG (2007). Stargazin attenuates intracellular polyamine block of calciumpermeable AMPA receptors. Nat Neurosci 10: 1260-1267.

Sutton MA, Schmidt EF, Choi KH, Schad CA, Whisler K, Simmons $\mathrm{D}$ et al (2003). Extinction-induced upregulation in AMPA receptors reduces cocaine-seeking behaviour. Nature 421: 70-75.
Tanaka H, Grooms SY, Bennett MV, Zukin RS (2000). The AMPAR subunit GluR2: still front and center-stage. Brain Res 886: 190-207.

Tsubokawa H, Oguro K, Masuzawa T, Nakaima T, Kawai N (1995). Effects of a spider toxin and its analogue on glutamate-activated currents in the hippocampal CA1 neuron after ischemia. J Neurophysiol 74: 218-225.

White SL, Schmidt HD, Vassoler FM, Pierce RC (2013). Acute cocaine increases phosphorylation of CaMKII and GluA1 in the dorsolateral striatum of drug naive rats, but not cocaineexperienced rats. Neurosci Lett 537: 71-76.

Wiggins A, Smith RJ, Shen HW, Kalivas PW (2011). Integrins modulate relapse to cocaine-seeking. J Neurosci 31: 16177-16184.

Wolf ME, Tseng KY (2012). Calcium-permeable AMPA receptors in the VTA and nucleus accumbens after cocaine exposure: when, how, and why? Front Mol Neurosci 5: 72.

Zhang L, Hsu FC, Mojsilovic-Petrovic J, Jablonski AM, Zhai J, Coulter DA et al (2015). Structure-function analysis of SAP97, a modular scaffolding protein that drives dendrite growth. Mol Cell Neurosci 65: 31-44.

Zheng CY, Seabold GK, Horak M, Petralia RS (2011). MAGUKs, synaptic development, and synaptic plasticity. Neuroscientist 17: 493-512.

Zheng Z, Keifer J (2014). Sequential delivery of synaptic GluA1- and GluA4-containing AMPA receptors (AMPARs) by SAP97 anchored protein complexes in classical conditioning. $J$ Biol Chem 289: 10540-10550.

Zhou W, Zhang L, Guoxiang X, Mojsilovic-Petrovic J, Takamaya K, Sattler R et al (2008). GluR1 controls dendrite growth through its binding partner, SAP97. J Neurosci 28: 10220-10233. 